\title{
Moscas ectoparasitas (Diptera, Hippoboscoidea) de morcegos (Mammalia, Chiroptera) do Estado do Paraná. II. Streblidae. Chave pictórica para gêneros e espécies ${ }^{1}$
}

\author{
Gustavo Graciolli ${ }^{2}$ \\ Claudio José Barros de Carvalho ${ }^{2}$
}

\begin{abstract}
Batflies (Diptera, Hippoboscoidea) from Paraná State. II. Streblidae. Pictorial key to genera and species. A survey of batflies (Diptera, Streblidae) was done in Paraná State, Brazil during 1998 and 1999. Twenty-tree species in 10 genera were recorded. Two species of streblid batflies, Paraeuctenodes longipes Pessôa \& Guimarães, 1936 and Metelasmus pseudopterus Coquillett, 1907, that have not been found in Paraná State were included, because they have been recorded in Rio Grande do Sul and São Paulo States. One species is new a record for Brazil: Trichobius jubalus Wenzel, 1976. In addition, twenty more species are new records for Paraná State: Trichobius joblingi Wenzel, 1966; T. tiptoni Wenzel, 1976; T. furmani Wenzel, 1966; T. longipes (Rudow, 1871); Paratrichobius longicrus (Ribeiro, 1907); Megistopoda aranea (Coquillett, 1899); M. proxima (Séguy, 1926); Aspidoptera falcata Wenzel, 1976; A. phyllostomatis (Perty, 1833); Exastinion clovisi (Pessôa \& Guimarães, 1936); Noctiliostrebla aitkeni Wenzel, 1966; Paradyschiria fusca Speiser; 1900; P. parvula Falcoz, 1931; Strebla chrotopteri Wenzel, 1976; S. diaemi Wenzel, 1966; S. guajiro (Garcia \& Casal, 1965); S. mirabilis (Waterhouse, 1879), Paraeuctenodes similis Wenzel, 1976; Anastrebla caudiferae Wenzel, 1976; A. modestini Wenzel, 1966. The occurence of Paratrichobius longicrus on Pygoderma bilabiatum (Wagner, 1843), and Trichobius dugesioides dugesioides and Strebla mirabilis on Mimon bennettii (Gray, 1838) is reported for first time. Pictorial keys to species are presented and the gonopods of streblid batflies are illustrated.

KEY WORDS. Streblidae, Chiroptera, Paraná, ectoparasitism, batflies
\end{abstract}

Streblidae é uma família formada por moscas hematófagas ectoparasitas de morcegos, que inclue espécies ápteras, braquípteras e aladas. É encontrada em todas as regiões biogeográficas e, principalmente em áreas tropicais (WENZEL 1970). São reconhecidas cinco subfamílias, três exclusivas do Novo Mundo: Trichobiinae com 19 gêneros, Streblinae com quatro gêneros e Nycterophiliinae com dois gêneros. Duas são exclusivas do Velho Mundo: Nycteriboscinae com cinco gêneros e Ascopterinae com um (WENZEL \& PETERSON 1987). O maior número de espécies da família, ou seja, 152 das 224 reconhecidas é encontrado no continente americano (Guerrero \& Morales-Malacara 1996; Guerrero 1997, 1998a,b). No continente americano, os estréblidas parasitam morcegos das famílias Emballonuridae, Noctilionidae, Mormoopidae, Natalidae, Furipteridae, Vespertilionidae, Molossidae e, principalmente, Phyllostomidae.

1) Contribuição número 1271 do Departamento de Zoologia, Universidade Federal do Paraná.

2) Departamento de Zoologia, Universidade Federal do Paraná. Caixa Postal 19020, 81531-990 Curitiba, Paraná, Brasil. E-mail: mingau@bio.ufpr.br. 
Os principais trabalhos de levantamento taxonômico no Novo Mundo foram realizados no Panamá (Wenzel et al. 1966), Colômbia (MARINKelle \& Grose 1981), Venezuela (WENZEL 1976; GUERRERO 1993, 1994a,b, 1995a,b, 1996a) e Peru (GUERRERo 1996b). Segundo GuERRERo (1997), no Brasil foram registradas 42 espécies, número inferior aos registrados no Panamá com 69 espécies; Colômbia com 54 espécies; Venezuela com 119 espécies e Peru com 59 espécies. Estes números evidenciam a falta de amplos trabalhos de levantamento das espécies de estreblídeos em todas as regiões do Brasil.

Os trabalhos de levantamento no território brasileiro foram realizados em áreas restritas. Por exemplo, PESSÒA \& GUIMARÃES (1940) registraram seis espécies de cinco gêneros no Mato Grosso; GUIMARÃES (1944) registrou quatro espécies de três gêneros no Estado de São Paulo; WHITAKER \& MUMFORD (1977) registraram 10 espécies de oito gêneros e KOMENo \& LiNHARES (1999) 10 espécies de seis gêneros em Minas Gerais; CoIMBRA et al. (1984) 12 espécies de cinco gêneros no Distrito Federal; GUERRERo (1994a, 1994b, 1995a, 1995b, 1996a, 1997) registrou 22 espécies de nove gêneros na região amazônica e GRACIOLLI \& RUI (2001) registraram 11 espécies de sete gêneros no Rio Grande do Sul. Além disso, diversos trabalhos foram realizados a partir de coletas escassas, sem uma visão ampla da distribuição e das relações parasito-hospedeiro (MirANDA RibEIRO 1907; COSTA LIMA 1921; Kessel 1924, 1925; I’ESSÔA \& GUIMARÃES 1936; GARCIA \& CASAL 1965; SANTOS 1991).

Tendo em vista o apresentado acima, o presente trabalho teve como objetivo realizar um levantamento das espécies de Streblidae e seus hospedeiros no estado do Paraná.

\section{MATERIAL E MÉTODOS}

Foi obtido por empréstimo material coletado no Paraná proveniente das seguintes instituições: (DZUP) Coleção de Entomologia Padre Jesus Santiago Moure, Departamento de Zoologia, Universidade Federal do Paraná, Curitiba; (MHNCI) Museu de História Natural Capão da Imbuia, Curitiba; (MZSP) Museu de Zoologia da Universidade de São Paulo, São Paulo.

Além do material emprestado, foram examinados hospedeiros depositados em via líquida na Coleção de Vertebrados do Departamento de Zoologia da Universidade Federal do Paraná e, realizadas coletas em vários locais no estado do Paraná.

Para as capturas dos hospedeiros foram geralmente utilizadas redes de neblina ("mist-net") armadas em trilhas nas matas ou nas entradas de abrigos (cavernas, casas abandonadas, etc.). Para a identificação das espécies dos hospedeiros, foram utilizadas as chaves de VIzOTTO \& TADDEI (1973) e REIS et al. (1993). As identificações foram confirmadas pelo biólogo Michel Miretzki (Museu de História Natural Capão da Imbuia).

Todos os hospedeiros capturados eram revisados visualmente e os dípteros encontrados removidos com auxílio de pinças e tensores. Os ectoparasitos coletados foram fixados em álcool a $70^{\circ} \mathrm{GL}$ em recipientes de vidro transparente com $10 \mathrm{ml}$ 
de volume, contendo no seu interior uma etiqueta com informações sobre a espécie do hospedeiro, local e data de coleta, e coletor. Estes exemplares estão depositados na Coleção de Entomologia Pe. Jesus Santiago Moure (DZUP), da Universidade Federal do Paraná.

A terminologia adotada para a morfologia externa de Streblidae foi a proposta de Wenzel (1976) e Wenzel \& PeTERSON (1987). A seqüência de apresentação das espécies segue a proposta taxonômica de GUERRERO (1997). Todas as diagnoses genéricas foram modificadas de GUERRERO (1993, 1994a,b, 1995a, 1996a).

\section{RESULTADOS}

Foram obtidas 23 espécies pertencentes a 11 gêneros de Streblidae. Com exceção de Trichobius dugesioides dugesioides Wenzel, 1966 e Strebla wiedemanni Kolenati, 1856, todas as espécies são registradas pela primeira vez no estado do Paraná. Além destes registros para o Paraná. Trichobius jubatus Wenzel, 1976 é registrada pela primeira vez no Brasil. Paraeuctenodes longipes Pessôa \& Guimarães, 1936 e Metelasmus pseudopterus Coquillett, 1907 não foram encontradas entre o material paranaense examinado. No entanto, foram incluídas pois já tinham sido registradas nos estados adjacentes ao Paraná e além de seus hospedeiros ocorrerem no estado. Portanto, ainda provavelmente deverão ser coletadas. Para localidades e origem do material paranaense registrado neste trabalho ver tabela I.

\section{Streblidae Kolenati, 1856 \\ Trichobius Gervais, 1844}

Trichobius Gervais, 1844: 14; Speiser, 1900a: 33, 34, Syn.: Kolenatia; Kessel, 1925: 14 (diagnose e chave de identificação das espécies); Curran, 1935: 8 (chave de identificação das espécies); Jobling, 1938: 362, Syn.: Kesselia (revisão taxonômica,); Wenzel et al., 1966: 442 (criação de grupos morfológicos e chave de identificação das espécies); Guerrero, 1994a: 2 (diagnose); Guerrero, 1995a: 19 (chave de identificação das espécies).

Trichobia [sic]; Gervais, 1844; Guérin-Meneville, 1844: 556.

Kolenatia Rondani, 1878: 169.

Trichobius Townsend, 1891: 105, praeoc. (Gervais, 1844).

Kesselia Curran 1934: 522.

Espécie-tipo de Trichobius: Trichobius parasiticus Gervais, 1844, por monotipia.

Espécie-tipo de Kolenatia: Strebla widemanni Kolenati, 1856, por designação original.

Espécie-tipo de Kesselia: Kesselia pallida Curran, 1934, por monotípia.

Diagnose. Cabeça geralmente em forma de funil. Superfície dorsal sem subdivisões, com duas elevações ovais posteriores ou com os laterovértices e os lóbulos occipitais bem individualizados. Olho composto com uma a 36 facetas. Palpos planos, redondos, ovais ou com o extremo distal reto, com setas na margem ou com a metade da superfície ventral coberta de setas. Tórax tão alto quanto largo ou um pouco mais largo; mesonoto convexo ou reto, com a margem anterior arredondada ou reta. Sutura transversal completa e bem definida; sutura mediana reta, unida ou não à sutura transversal ou em forma de "Y" invertido. Mesosterno com o bordo anterior arredondado ou ligeiramente projetado entre as coxas e ligeiramente emarginado. Mesosterno 
Tabela I. Localidades com registros de espécies de Streblidae e Nycteribiidae no Estado do Paraná, Brasil. (AT) Almirante Tamandaré; (AR) Arapoti; (BS) Bocaiúva do Sul; (CL) Campo Largo; (CA) Cerro Azul; (CO) Colombo; (CT) Curitiba; (DN) Diamante do Norte; (FN) Fênix; (GA) Guaraqueçaba; (IM) Ilha do Mel; (LO) Londrina; (MT) Matinhos; (PL) Palmeira; (PA) Paranaguá; (PI) Parque Nacional do Iguaçu; (PM) Parque Estadual Marumbi; (OT) Ortigueira; (RB) Rio Branco do Sul; (SS) São Jerônimo da Serra; (TB) Três Barras do Paraná; (TP) Tunas do Paraná; (WB) Wenceslau Braz. (A) Material proveniente de coletas no período de 1998 a 1999; (B) material proveniente do DZUP; (C) material proveniente do $\mathrm{MHNCl}$; (D) material retirado de hospedeiros depositados na Coleção de Vertebrados, Departamento de Zoologia, Universidade Federal do Paraná; (E) registro na literatura.

\begin{tabular}{|c|c|c|c|c|c|c|c|c|c|c|c|c|c|c|c|c|c|c|c|c|c|c|}
\hline \multirow{2}{*}{ Táxons } & \multicolumn{22}{|c|}{ Localidades } \\
\hline & AT & AR & $C L$ & CA & $\mathrm{CO}$ & CT & DN & $\mathrm{FN}$ & GA & $\mathrm{IM}$ & LO & MT & PA & PI & PM & OT & RB & SS & TB & TP & WB & Total \\
\hline $\begin{array}{l}\text { Trichobius joblingi } \\
\text { Trichobius tiptoni }\end{array}$ & & & & & & & & & $\mathrm{XA}$ & & XA & & & $X A$ & & & & & & & & $\begin{array}{l}2 \\
1\end{array}$ \\
\hline Trichobius d. dugesioides & XE & & & & XA & & & & & $X D$ & & & $\mathrm{XC}$ & & & $X E$ & & & XA & & & 6 \\
\hline Trichobius furmani & $X B$ & & & & & & & & & & & & & & & & $\mathrm{XB}$ & & & & & 2 \\
\hline Trichobius longipes & & & & & & & & $\mathrm{XA}$ & & & & & & & & & & & & & & 1 \\
\hline Trichobius jubatus & & & & & & & $\mathrm{xC}$ & & & & & & & & & & & & & & & 1 \\
\hline Paratrichobius longicrus & & $\mathrm{XC}$ & & & & XAC & & & & & XA & $x C$ & & XA & & & & & & & & 5 \\
\hline Megistopoda aranea & & & & & & & & & & & & & & XA & & & & & & & & 1 \\
\hline Megistopoda proxima & & & & & & $\mathrm{XB}$ & & & & & $\mathrm{XA}$ & & & $X A$ & & & & & $\mathrm{XA}$ & & & 4 \\
\hline Aspidoptera falcata & & & & & & & & & & & & & & $X A$ & & & & & & & & 1 \\
\hline Aspidoptera phyllostomatis & & & & & & & & & & & & & & XA & & & & & & & & 1 \\
\hline Exastinion clovisi & & & & & & XA & & & & & & & & & & & & & & & & 1 \\
\hline Noctiliostrebla aitkeni & & & & & & & & & XA & & XA & $X A$ & & & & & & & & & & 3 \\
\hline Paradyschiria fusca & & & & & & & & & $\mathrm{XA}$ & & XA & $\mathrm{XA}$ & & & & & & & & & & 3 \\
\hline Paradyschiria parvula & & & & & & & $\mathrm{XC}$ & & & & & & & & & & & & & & & 1 \\
\hline Strebla chrotopteri & & & & & & & & & & & & & & XA & & & & & & & & 1 \\
\hline Strebla diaemi & & & & $\mathrm{XB}$ & & & & & & & & & & & & & & & & & & 1 \\
\hline Strebla guajiro & & & & & & & & & & & & & & $X A$ & $X D$ & & & & & & & 2 \\
\hline Strebla mirabilis & & & & & & & & & & & & & & $\mathrm{XA}$ & & & & & & & & 1 \\
\hline Strebla wiedemanni & $X B E$ & & $\mathrm{XA}$ & & & & & & & & & & & & & & $\mathrm{XE}$ & $X E$ & & & $X E$ & 5 \\
\hline Paraeuctenodes similis & & & & & & & & & & & & & & & XD & & & & & & & 1 \\
\hline Anastrebla caudiferae & & & & & & & & & & & & & & & & & & & & $\mathrm{XC}$ & & 1 \\
\hline Anastrebla modestini & & & & & & XA & & & & & & & & & & & & & & & & 1 \\
\hline Total & 3 & 1 & 1 & 1 & 1 & 4 & 2 & 1 & 3 & 1 & 5 & 3 & 1 & 9 & 2 & 1 & 2 & 1 & 2 & 1 & 1 & 45 \\
\hline
\end{tabular}


com ou sem lobo metasternal. Asas desenvolvidas, com as veias usuais. Pernas geralmente curtas, subiguais, ou com o par posterior mais longo, neste tíbias cilíndricas e retas. Margem superior das tíbias sem macrosetas, em alguns casos com setas um pouco mais longas que o resto. Abdômen: Fêmeas. Tergito VII às vezes unido ao epiprocto e de difícil delimitação entre as placas, com número variável de setas. Lado ventral somente com esternito VII, podendo estar dividido ou não. Machos. Esternitos $\mathrm{V}$ e VI presentes, ausentes ou apenas um deles presente. Sintergosternito VII+VIII e Tergito IX individualizados. Gonópodos variáveis, sempre delgados e finos e relativamente robustos, com o par de setas variáveis, seta acessória anterior ou posterior à macroseta. Edeago fino, longo e enrolado.

Cometário. Gênero com atualmente 68 espécies válidas (GUERRERO 1993, 1998a,b; GUERRERO \& MORALES-MALACARA 1996). No Brasil foram registradas 10 espécies (GUERRERO 1997). Parasitam morcegos embalonurídeos, noctilionídeos, vespertilionídeos, molossídeos mormoopídeos e filostomídeos. No Brasil, foram encontrados principalmente no último grupo citado.

\section{Trichobius joblingi Wenzel, 1966}

Fig. 1

Trichobius dugesii; Guimarães, 1937: fig. 6; Jobling, 1949b: 316 (registro). Erro de identificação.

Trichobius blandus; Jobling, 1938: 385 (redescrição). Erro de identificação.

Trichobius joblingi Wenzel, 1966 in Wenzel et al., 1966: 481, localidade-tipo: Summit Golf Club, Canal Zone, Panamá; Guerrero, 1995a: 3 (diagnose); Guerrero, 1998a: 2 (variação morfológica).

Diagnose. Cabeça: laterovértices e lóbulos occipitais bem esclerotinizados e distintos. Laterovértice com cinco macrosetas e duas setas pequenas, uma na base da antena, outra anterior ao olho composto. Lóbulo occipital com oito a nove macrosetas e duas setas menores na margem posterior. Olho composto com 10 a 11 facetas. Tórax: prescuto com microtríquias apenas no bordo externo. Sutura longitudinal não encontrando a sutura transversal. Setas antescutelares duas a três vezes mais longas que as setas imediatamente anteriores a elas. Lóbulo metasternal trapezóide, curvado dorsalmente, não unido ao metepímero. Abdômen: lóbulo do sintergito I+II com 20 a 24 setas.

Fêmea. Abdômen: Conetivo abdominal, posteriormente ao lóbulo do sintergito I+II, com quatro a cinco setas mais largas, de difícil observação em indivíduos com abdômen contraído, seguidas de pequena área glabra e, após, uma faixa de setas mais longas que as outras do conetivo, iniciando do terceiro espiráculo e terminando entre o quinto e sexto espiráculo. Tergito VII pequeno, pouco esclerotinizado, com dois pares de setas; um par anterior mais longo e mais externo e um par posterior mais interno. Epiprocto com quatro macrosetas distais, com o par lateral mais largo e longo do que o par central, e um par de setas laterais menores. Esternito VII dividido em dois escleritos ovais com 11 a 12 setas em cada um.

Macho. Abdômen: Esternito V presente. Esternito VI filiforme. Sintergosternito VII+VIII com cinco a seis setas de cada lado. Tergito IX com 11 a 14 setas. Gonópodos assimétricos, em vista lateral, quase retilíneos, levemente curvado ventralmente, com uma fila de setas ventrais entre a macroseta e o ápice. Poucas setas laterais e uma dorsal no terço distal (Fig. 1). 

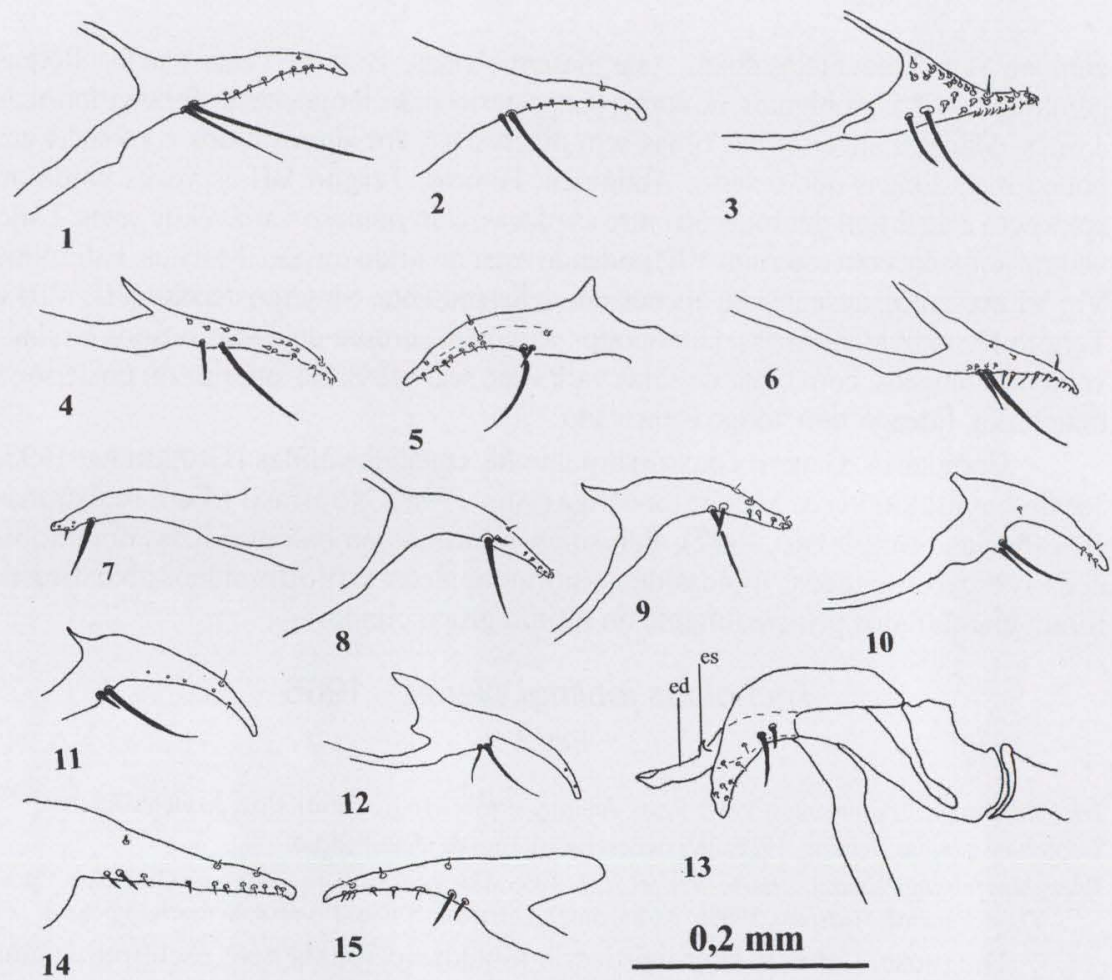

Figs 1-15. Gonópodos de Trichobiinae. (1) Trichobius joblingi; (2) Trichobius tiptoni; (3) Trichobius dugesioides dugesioides; (4) Trichobius furmani; (5) Trichobius longipes; (6) Trichobius jubatus; (7) Paratrichobius longicrus; (8) Megistopoda aranea; (9) Megistopoda proxima; (10) Aspidoptera falcata; (11) Aspidoptera phyllostomatis; (12) Exastinion clovisi; (13) Noctiliostrebla aitkeni; (14) Paradyschiria fusca; (15) Paradyschiria parvula. (ed) Edeago, (es) espinho.

Hospedeiro-tipo. Carollia perspicillata (Linnaeus, 1758) (Phyllostomidae). Outros hospedeiros: Rhinchonycteris naso (Wied-Newied, 1820), Saccopterix bilineata (Temmick, 1838) (Emballonuridae); Noctilio leporinus (Linnaeus, 1758) (Noctilionidae); Pteronotus parnellii (Gray, 1843) (Mormoopidae); Anoura caudifer (E. Geoffroy, 1818), A. geoffroyi Gray, 1838, Artibeus anderseni Osgood, 1916, A. hartii Thomas, 1892, A. jamaicensis Leach, 1821, A. lituratus (Olfers, 1818), A. obscurus Schinz, 1821, Carollia brevicauda (Schinz, 1821), C. castanea H. Allen, 1890, C. subrufa (Hahn, 1905), Chiroderma villosum Peters, 1860, Desmodus rotundus (E. Geoffroy, 1810), Glossophaga soricina (Pallas, 1766), Lonchophylla robusta Miller, 1912, Lonchorhina aurita Tomes, 1863, Macrophyllum macrophyllum (Schinz, 1821), Micronycteris brachyotis (Dobson, 1879), M. megalotis (Gray, 1842), M. minuta (Gervais, 1856), M. nicefori Sanborn, 1949, Phyllostomus discolor Wagner, 1843, P. elongatus (E. Geoffroy, 1810), P. hastatus (Pallas, 1767), P. latifolius (Thomas, 1901), Platyrrhinus helleri (Peters, 1866), Rhinophylla 
pumilio Peters, 1865, Sturnira erythromos (Tschud, 1844), S. lilium (E. Geoffroy, 1810), S. ludovici Anthony, 1924, S. tildae de la Torre, 1959, Tonatia silvicola (d'Orbigny, 1836), Trachops cirrhosus (Spix, 1823), Uroderma bilobatum Peters, 1866, Vampyrodes caraccioli (Thomas, 1889) (Phyllostomidae); Myotis nigricans (Schinz, 1821), Myotis sp. (Vespertilionidae); e Molossus ater E. Geoffroy, 1805, M. molossus (Pallas, 1766) (Molossidae).

Distribuição geográfica. México, Belize, Guatemala, El Salvador, Nicarágua, Costa Rica, Panamá, Trinidad e Tobaco, Venezuela, Colômbia, Suriname, Guiana, Guiana Francesa, Brasil (Pará, Rondônia, Distrito Federal, Minas Gerais, São Paulo, Paraná), Peru, Bolívia, Paraguai.

Material paranaense examinado. Londrina: Parque Arthur Thomas, 5 machos e 7 fêmeas em Carollia perspicillata, Graciolli \& Lima leg., 12/IX/1998; Foz do Iguaçu: Parque Nacional do Iguaçu, 1 macho em C. perspicillata, Graciolli, Lima \& Rocha leg., 14/X/1998. 1 macho em C. perspicillata, Graciolli, Lima \& Rocha leg., 16/X/1998; 8 machos e 2 fềmeas em C. perspicillata, Graciolli, Lima \& Rocha leg., 14/I/1999.

Material adicional examinado. PANAMÁ: Canal Zone, 1 mile from Gatluncillo, hollow tree, 10 machos e 10 fêmeas em Carollia perspicillata azteca, Keenan \& Tipton leg., C. M. Keenan \& V. J. Tipton leg, 28/VII/1960 (MZSP).

Comentário. Trichobius joblingi é um parasito típico de C. perspicillata, apesar de ser encontrado parasitando um grande número de outras espécies de morcegos. Carollia perspicillata é, provavelmente, a espécie mais comum de morcego em toda a Região Neotropical (GUERRERO 1998a) e em toda sua distribuição geográfica é parasitada por $T$. joblingi.

\section{Trichobius tiptoni Wenzel, 1976}

Fig. 2

Trichobius tiptoni Wenzel, 1976: 60, localidade-tipo: Altamira, Barinas, Venezuela; Guerrero, 1995a: 7 (diagnose).

Diagnose. Cabeça: laterovértices e lóbulos occipitais bem esclerotinizados e distintos. Laterovértice com cinco setas. Lóbulo occipital com sete setas e duas menores no bordo anterior. Olho composto com 12 facetas. Tórax: sutura longitudinal não encontrando a sutura transversal. Setas antescutelares cerca de quatro a cinco vezes mais longas que as discais do escuto. Macrosetas nas bordas do prescuto e do escutelo muito longas, setas discais pequenas. Lóbulo metasternal trapezóide, curvado dorsalmente, não unido ao mesepímero. Abdômen: Lóbulo do sintergito I+II com 20 a 21 setas.

Fêmea. Abdômen: Posteriormente ao lóbulo do sintergito I+II, cerca de quatro setas mais longas e largas que as outras no conetivo lateral. Tergito VII com duas setas maiores laterais e duas menores entre as anteriores. Epiprocto com quatro macrosetas distais e um par de setas laterais com metade do tamanho das macrosetas. Esternito VII pequeno, dividido em dois escleritos ovais com 13 a 14 setas em cada um.

Macho. Abdômen: Esternito $\mathrm{V}$ com setas da margem posterior duas vezes o comprimento das discais. Esternito VI filiforme. Sintergosternito VII+VIII com oito 
a 11 setas e uma menor dorsal. Tergito IX com 11 a 14 setas. Gonópodos levemente curvados a partir da macroseta; inserção da seta acessória anterior à macroseta; nove setas laterais e uma dorsal (Fig. 2).

Hospedeiro-tipo. Anoura caudifer (Phyllostomidae). Outros hospedeiros: Anoura geoffroyi, Anoura sp., Artibeus jamaicensis, Carollia castanea, C. perspicillata, Chrotopterus auritus (Peters, 1856), Desmodus rotundus, Platyrrhinus helleri, Sturnira lilium e S. ludovici (Phyllostomidae).

Distribuição geográfica. Venezuela, Guiana Francesa e Brasil (Minas Gerais, Paraná, Rio Grande do Sul).

Material paranaense examinado. Guaraqueçaba: Ilha do Rabelo, 1 fềmea em Anoura caudifer, Althoff, S. L. \& A. P. Nascimento leg., 14/XII/1992.

Material adicional examinado. Brasil, Rio Grande do Sul: Dom Pedro de Alcântara, 4 machos em Anoura caudifer, Grillo leg., 07/IX/1997 (DZUP); 1 fềmea em A. caudifer, Grillo col., 08/IX/1997 (DZUP); 1 macho em Anoura geoffroyi, Grillo leg., 07/IX/1997 (DZUP).

Comentário. Parasito primário de Anoura Gray, 1838. É encontrado sobre este hospedeiro em toda a sua distribuição geográfica. Na Venezuela, WENZEL (1976: 61) e GUERRERO (1995a) encontraram, respectivamente, cerca de 95\% e 81\% dos exemplares de T. tiptoni sobre Anoura caudifer. No estado do Rio Grande do Sul, GRACIOLLI e RUI (2001) encontraram cerca de $86 \%$ dos individuos de T. tiptoni sobre este mesmo hospedeiro e o restante sobre Anoura geoffroyi.

\section{Trichobius dugesioides dugesioides Wenzel, 1966}

Fig. 3

Trichobius dugesioides Wenzel, 1966 in Wenzel et al., 1966: 488, localidade-tipo: Chepo Road, Panamá. Trichobius dugesioides dugesioides; Guerrero, 1995a: 10 (diagnose).

Diagnose. Cabeça: laterovértices e lóbulos occipitais bem esclerotinizados e distintos. Laterovértice com cinco setas longas e uma diminuta à frente dos olhos. Lóbulo occipital com nove setas longas e um par de outras diminutas no bordo posterior. Olho composto com cerca de dez facetas. Tórax: mesonoto totalmente coberto de setas. Sutura longitudinal não encontrando a sutura transversal. Setas antescutelares com aproximadamente o dobro do tamanho das anteriores a elas. Margem anterior do mesosterno estendendo-se entre as procoxas. Lóbulo metasternal ausente. Asa, 1A sem setas na base. Abdômen: Lóbulo do sintergito I+II com cerca de 28 setas.

Fêmea. Abdômen: Grupo de 10 a 15 setas mais longas do que as outras do conetivo lateral atrás do lóbulo do sintergito I+II. Tergito VII pequeno, pouco esclerotinizado com dois pares de setas, um par de macrosetas laterais e um par de setas menores mais internas. Epiprocto com quatro macrosetas distais. Esternito VII dividido em dois escleritos ovais com 15 a 16 setas em cada um.

Macho. Abdômen: Esternito V amplo e retangular com as setas da margem posterior mais longas, aproximadamente o dobro em comprimento das discais. Esternito VI ausente. Sintergosternito VII+VIII com oito setas de cada lado. Tergito IX com setas em três filas laterais. Gonópodos com estreitamento brusco em direção 
ao ápice; inserção da seta acessória anterior à macroseta, cerca de 20 setas espiniformes laterais e uma fila ventral (Fig. 3).

Hospedeiro-tipo. Trachops cirrhosus (Phyllostomidae). Outros hospedeiros: Mormoops megaphylla (Peters, 1864) (Mormoopidae); Artibeus jamaicensis, A. lituratus, Carollia brevicauda, C. castanea, C. perspicillata, Chiroderma villosum, Chrotopterus auritus, Desmodus rotundus, Glossophaga soricina, Lonchorhina aurita, Macrophyllum macrophyllum, Mimon bennettii (Gray, 1838), Phyllostomus discolor, P. elongatus, P. hastatus, Platyrrhinus helleri, Sphaeronycteris toxophyllum Peters, 1882, Sturnira lilium, Tonatia bidens (Spix, 1823), T. silvicola, Tonatia sp., Uroderma bilobatum (Phyllostomidae); Natalus stramineus Gray, 1838 (Natalidae); Molossus molossus e M. sinaloae J.A. Allen, 1906 (Molossidae).

Distribuição geográfica. Guatemala, Nicarágua, Panamá, Venezuela, Colômbia, Guiana Francesa, Brasil (Pará, Distrito Federal, São Paulo, Paraná), Peru e Bolívia.

Material paranaense examinado. Colombo: 4 machos e 2 fêmeas em Mimon bennettii, Graciolli leg., 25/VI/1998; Ilha do Mel: 2 machos em M. bennettii (Coleção de Vertebrados do Depto. de Zoologia, UFPR), 24/VIII/1985; Ortigueira: 3 machos e 2 fêmeas em Chrotopterus auritus, Dos Santos leg., 31/I/1986; Paranaguá: Reflorestadora Banestado, 3 machos e 3 fêmeas em Artibeus lituratus, 14/XI/1991 (MHNCI); Três Barras do Paraná: Reserva Guarani, 3 machos e 1 fêmea em C. auritus, Tiepolo \& Marcondes leg., 27/V/1998.

Material adicional examinado. PANAMÁ: Chepo Road (Culvert), 2 machos e 2 fêmeas (PARÁTIPOS) em Trachops c. cirrhosus, Keenan \& Tipton leg. 12/X/1959 (MZSP).

Comentário. Este éo primeiro registro de uma espécie de Streblidae parasitando M. bennettii. SANTOS (1991) registrou a primeira ocorrência de $T$. dugesioides sobre C. auritus no Estado do Paraná. Em algumas fêmeas, o abdômen apresentava-se contraído ou dobrado sob o lóbulo do sintergito I+II, dificultando a visualização da setação, sendo observadas somente três a oito setas mais fortes atrás do lóbulo.

\section{Trichobius furmani Wenzel, 1966}

Fig. 4

Trichobius furmani Wenzel, 1966 in Wenzel et al., 1966: 490, localidade tipo: Sagrario, Puno, Peru; Guerrero, 1995a: 11 (diagnose).

Diagnose. Cabeça: laterovértices e lóbulos occipitais bem esclerotinizados e distintos. Laterovértice com cinco setas. Lóbulo occipital com oito setas. Olho composto com 11 facetas. Tórax: Sutura longitudinal não encontrado a sutura transversal. Setas discais do mesonoto quatro a cinco vezes mais curtas que as ântero-laterais. Setas antescutelares cerca de quatro vezes mais longas que as anteriores. Lóbulo metasternal ausente. Pernas curtas e subiguais. Asa, veia $1 \mathrm{~A}$ sem setas na base. Abdômen: Setas ventrais do conetivo abdominal mais longa do que as outras do conetivo. Lóbulo do sintergito I+II com cerca de 29 setas.

Fêmea. Abdômen: Tergito VII com duas macrosetas medianas laterais e um par de outras menores posteriores entre as macrosetas. Epiprocto com quatro 
macrosetas distais. Esternito VII dividido em dois escleritos elípticos com 15 a 24 setas em cada um.

Macho. Abdômen: Esternito V com as setas da margem posterior mais longas e largas que as setas discais. Esternito VI ausente. Sintergosternito VII+VIII com oito setas de cada lado. Tergito IX com 17 setas de cada lado. Gonópodos finos, delicados, levemente curvados no ápice; inserção da seta acessória anterior à macroseta (Fig. 4).

Hospedeiro-tipo. Desmodus rotundus (Phyllostomidae). Outros hospedeiros: Diphylla ecaudata Spix, 1823, Glossophaga soricina (Phyllostomidae); e Molossus molossus (Molossidae).

Distribuição geográfica. Colômbia, Brasil (Distrito Federal e Paraná), Peru, Bolívia e Paraguai.

Material paranaense examinado: Almirante Tamandaré: 1 macho e 1 fêmea em Desmodus rotundus, Silva leg., 30/IV/1985 (DZUP); Rio Branco do Sul: 3 machos e 2 fêmeas em D. rotundus, Dos Santos leg., 21/VI/1988.

Comentário. Segundo GuerRero (1995a), esta espécie parece substituir Trichobius parasiticus Gervais, 1844 como o parasito típico de D. rotundus em algumas áreas da América do Sul. Anteriormente, COIMBRA et. al. (1984) encontraram T. furmani no Distrito Federal parasitando D. rotundus e D. ecaudata.

\section{Trichobius longipes (Rudow, 1871)}

Fig. 5

Strebla longipes Rudow, 1871: 121, localidade tipo: não determinada.

Trichobius dugesii; Kessel, 1925: 16 (diagnose); Jobling, 1938: 383 (redescrição). Erro de identificação. Trichobius phyllostomae; Curran, 1934: 523. Erro de identificação.

Trichobius mixtus Curran, 1935: 10, localidade-tipo: Chilibrillo Caves, Panamá, Panamá; Guimarães, 1937: 654 (redescrição).

Trichobius longipes; Wenzel et al., 1966: 466, Syn.: mixtus (redescrição); Guerrero, 1994a: 13 (diagnose).

Diagnose. Cabeça: laterovértices e lóbulos occipitais bem esclerotinizados e distintos. Laterovértice com cinco macrosetas mais duas setas pequenas, uma próxima da base das antenas e outra anterior ao olho composto. Lóbulo occipital com sete a oito macrosetas e uma a duas diminutas no bordo posterior. Olhos composto com 11 a 12 facetas. Margens da cavidade bucal fortemente convergentes, em forma de "V". Tórax: Sutura longitudinal não encontrando a sutura transversal. Prescuto com duas filas de macrosetas laterais, quatro a cinco vezes mais longas que as discais; tamanho das setas do prescuto diminuindo gradativamente das margens para a parte discal. Setas discais com $1 / 4$ a 1/5 do tamanho das macrosetas laterais. Setas antescutelares não diferenciadas das outras setas do escuto, com exceção de duas setas em cada lado do escuto com o dobro do comprimento das demais. Asa: normal, veia 1A sem cerdas dorsais na base. Lóbulo metasternal largo e triangular, unido ao metepímero.

Fêmea. Abdômen: Conetivo abdominal lateral com cerca de 34 setas mais largas que as outras do conetivo entre o sintergito I+II e o esternito II. Tergito VII 
pequeno e retangular, com duas macrosetas laterais e um par de setas duas a três vezes mais curtas entre elas. Epiprocto curto, com quatro macrosetas distais e uma mais curta de cada lado. Esternito VII dividido em dois escleritos ovais com 14 setas em cada um.

Macho. Abdômen: Esternito V largo e retangular, com setas da margem posterior mais largas que as discais. Esternito VI filiforme. Sintergosternito VII+ VIII com 10 a 13 setas. Tergito IX com seis macrosetas e 22 a 26 setas menores de cada lado. Gonópodos curvados ventralmente; inserção da seta acessória anterior à macroseta; sete setas ventrais e três laterais, uma espiniforme anterior à seta acessória e uma dorsal (Fig. 5).

Hospedeiro-tipo. Phyllostomus hastatus (Phyllostomidae). Outros hospedeiros: Rhynchonycteris naso (Emballonuridae); Noctilio leporinus (Noctilionidae); Pteronotus parnellii (Mormoopidae); Anoura geoffroyi, Artibeus jamaicensis, Carollia perspicillata, Choeronycteris mexicana Tschudi, 1844, Desmodus rotundus, Glossophaga soricina, Phyllostomus discolor, P. elongatus, Sturnira ludovici, Uroderma bilobatum, Vampyrum spectrum (Linnaeus, 1758) (Phyllostomidae); e Molossus ater (Molossidae).

Distribuição geográfica. Estados Unidos, Cuba, Guatemala, Costa Rica, Panamá, Trinidad e Tobago, Venezuela, Colômbia, Guiana, Suriname, Brasil (Pará, Rondônia, Minas Gerais, São Paulo, Paraná), Peru e Bolívia.

Material paranaense examinado. Fênix: Parque Estadual Vila Rica do Espírito Santo, 1 macho em Phyllostomus hastatus, Miretzki leg., 21/X/1998.

Material adicional examinado: PANAMÁ: Chilibrillo Caves, 1 macho e 1 fêmea, Keenan \& Tipton leg. 17/VII/1959 (MZSP); BRASIL: Pará, Itaituba, Km 65 Transamazônica, 3 machos e 7 fêmeas em Uroderma b. bilobatum, S.A. Marques leg. 23/I/1979 (MZSP).

Comentário. Phyllostomus hastatus é parasitado por T. longipes em toda a sua distribuição geográfica (GUERRERO 1994a).

\section{Trichobius jubatus Wenzel, 1976}

Fig. 6

Trichobius jubatus Wenzel, 1976: 76, localidade-tipo: Hato Cariben, Rio Cinaruco, Apure, Venezuela; Guerrero, 1995a: 16 (diagnose).

Diagnose. Cabeça: laterovértices e lóbulos occipitais bem esclerotinizados e distintos. Laterovértice com oito macrosetas e dois grupos de outras menores anteriores; um grupo na base das antenas com quatro setas e outro grupo anterior ao olho composto com mais ou menos seis setas. Lóbulo occipital com 16 a 19 setas e quatro a sete outras menores no bordo posterior. Olho composto com 11 a 12 facetas. Tórax: Mesonoto convexo, muito setoso com cerca de 198 setas. Setas anteriores do prescuto um pouco maiores do que as discais. Sutura longitudinal não alcançando a sutura transversal. Setas antescutelares três a quatro vezes mais longas do que as da fila anterior. Lóbulo metasternal estreito e unido ao metepímero. Perna: Mesofêmur e mesotíbia com duas fileiras de setas paralelas, mais largas na porção ventral; metafêmur e metatíbia com apenas uma fileira anteroventral. Abdômen: 
Conetivo abdominal com um grupo de 10 setas, mais fortes atrás do lóbulo do sintergito I+II.

Fêmea. Abdômen: Conetivo abdominal coberto de setas com exceção da face dorsal; face ventral, duas setas lateroposteriores, próximas ao esternito VII, mais longas que este esternito e mais larga que outras setas do conetivo. Tergito VII quase imperceptível, com um par de setas muito pequenas. Epiprocto pouco esclerotinizado com quatro macrosetas finas distais e uma fila anterior de seis setas menores, três de cada lado. Esternito VII dividido em dois escleritos com mais ou menos 60 setas em cada um.

Macho. Abdômen: Lóbulo do Sintergito I+II com 14 macrosetas. Esternito $\mathrm{V}$ pouco esclerotinizado e coberto de setas. Esternito VI filiforme. Sintergosternito VII+VIII com mais ou menos 30 setas de cada lado. Tergito IX com mais ou menos 29 setas, sendo quatro macrosetas, de cada lado. Gonópodo levemente curvado no ápice, inserção da seta acessória anterior à macroseta longa, a qual ultrapassa o ápice do gonópodo (Fig. 6).

Hospedeiro-tipo. Molossus ater (Molossidae). Outro hospedeiro: Molossus molossus (Molossidae).

Distribuição geográfica. Venezuela e Brasil (Paraná).

Material paranaense examinado. Diamante do Norte: 1 macho e 2 fềmeas em Molossus ater (MHNCI), 28/IX/1994.

Comentário. Anteriormente a este trabalho, este grupo raro de espécies do gênero Trichobius estava restrito ao Caribe e à Venezuela. GUERRERO (1995a), no entanto, destacou que pela dificuldade de coleta de morcegos molossídeos, que são seus hospedeiros, deve existir um grande número de espécies não descritas. WENZEL et al. (1966: 474) comentaram possuírem exemplares de uma espécie não descrita pertencente ao grupo dunni, sem registro de hospedeiro, coletados no Brasil.

\section{Paratrichobius Costa Lima, 1921}

Paratrichobius Costa Lima, 1921: 20; Kessel, 1925: 19 (diagnose); Jobling, 1939: 490 (diagnose); Wenzel et al., 1966: 535 (chave de identificação das espécies); Wenzel, 1976: 86 (chave de identificação das espécies); Guerrero, 1994b: 174 (diagnose e chave de identificação das espécies). Espécie-tipo: Trichobius longicrus Miranda Ribeiro, 1907, por monotipia.

Diagnose. Cabeça: lóbulos occipitais e laterovértices visíveis, mas como zonas de alta concentração de microtríquias. Olhos grandes, sobressaindo ligeiramente do bordo da cabeça, com 25 a 30 facetas. Palpos arredondados ou ovais, com setas marginais e com pelo menos a metade basal de sua superfície ventral coberta de setas longas. Lado inferior da cabeça com setas espiniformes. Tórax: igual ou mais alto do que largo, com os ângulos anteriores geralmente arredondados com uma projeção central do prescuto mais ou menos desenvolvida. Sutura mediana reta e longa, não unida à sutura transversal a qual é interrompida no centro do mesonoto. Lado ventral arredondado, em forma de escudo; mesosterno projetado entre as coxas, com o bordo anterior da projeção arredondado ou truncado, apenas um pouco descolado nos lados. Lóbulo metasternal não unido ao mesepímero. Asas normais em suas veias e setas. Pernas: profêmures com uma fila de espinhos ou setas muito 
fortes no lado interno e ou sem dois a três espinhos mais curtos. Margem dorsal das tíbias sem setas longas. Pernas posteriores muito longas e, as vezes também as medianas, com os fêmures duas ou três vezes mais longos que o tórax. Tíbias posteriores muito longas, curvadas.

Fêmea. Abdômen: Tergito VII bem definido, transversal e separado da epiprocto, esta com quatro macrosetas discais.

Macho. Abdômen: Esternito V amplo. Sintergosternito VII+VIII e Tergito IX bem separados entre si. Gonópodos quase retos, geralmente, com o par de setas muito longas no ápice e sempre com a setas acessória distal à macroseta.

Comentário. São reconhecidas seis espécies de Paratrichobius (GUERRERo 1994b). No Brasil, foram registradas a ocorrência de Paratrichobius dunni (Curran, 1934) e P. salvini Wenzel, 1966 (GUERrero 1995b) e P. longicrus (Miranda Ribeiro, 1907) (MIRANDA RIBEIRO 1907; WHITAKER \& MUMFORD 1977; GUERRERO 1997; KOMENO \& LINHARES 1999).

\section{Paratrichobius longicrus (Miranda Ribeiro, 1907)}

Fig. 7

Trichobius longicrus Miranda Ribeiro, 1907: 236, localidade tipo: Quinta da Boa Vista, Rio de Janeiro, Rio de janeiro, Brasil.

Paratrichobius longicrus; Costa Lima, 1921: 20; Jobling, 1939: 490 (redescrição); Wenzel et al., 1966: 519 (variação morfológica); Guerrero, 1994b: 175 (diagnose).

Diagnose. Cabeça: laterovértices e lóbulos occipitais distintos. Laterovértice com quatro macrosetas. Lóbulo occipital com cerca de nove setas, uma das quais muito mais longa. Pós-vértice em "V". Olho composto grande com cerca de 30 facetas. Tórax: sutura transversal incompleta, sutura longitudinal não alcançando a sutura transversal. Prescuto com sete setas na metade anterior; espaço entre o término da sutura longitudinal e a transversal com quatro filas transversal de setas. Escutelo com quatro macrosetas; par lateral, no mínimo, com metade do comprimento do par central. Profêmures com uma fila de seis espinhos entre duas filas paralelas, uma composta de pequenas setas e a outra de macrosetas. Pernas posteriores muito longas, fêmures mais longos que o comprimento do corpo. Abdômen: esternito I com duas a três setas espiniformes na margem lateral. Conetivo abdominal dorsal apenas com duas filas paralelas longitudinais com quatro setas diminutas.

Fêmea. Abdômen: Lóbulo do Sintergito I+II com 11 setas. Tergito VII pequeno, transverso, reniforme ou em forma de meia lua, com duas macrosetas grandes anteriores e duas setas menores entre as macrosetas. Epiprocto com quatro macrosetas apicais ou subapicais e uma a três setas anteriores de cada lado. Esternito VII dividido em dois escleritos semicirculares, com duas macrosetas centrais maiores e 11 macrosetas menores em cada um.

Macho. Abdômen: Lóbulo do Sintergito I+II com 10 a 14 setas. Esternito II com setas discais espiniformes. Esternito $\mathrm{V}$ coberto de setas; margem posterior com duas macrosetas mais longas do que o esternito. Esternito VI ausente. Sintergosternito VII+VIII com uma macroseta dorsal e uma ou duas setas menores. Tergito IX com duas macrosetas dorsais e mais ou menos 11 setas de cada lado. Gonópodos assimétricos, um mais fino que o outro (Fig. 7). 
Hospedeiro-tipo. Artibeus jamaicensis (Phyllostomidae). Outros hospedeiros: Noctilio albiventris Desmarest, 1818 (Noctilionidae); Artibeus aztecus Andersen, 1906, A. cinereus (Gervais, 1856), A. concolor Peters, 1865, A. fimbriatus Gray, 1838, A. hartii, A. lituratus, A. toltecus (Saussure, 1860), Carollia perspicillata, Desmodus rotundus, Mesophylla macconnelli Thomas, 1901, Glossophaga soricina, Phyllostomus hastatus, Platyrrhinus aurarius (Handley \& Ferris, 1972), P. brachycephalus (Rouk \& Carter, 1972), P. dorsalis (Thomas, 1900), P. lineatus (E. Geoffroy, 1810), P. vittatus (Peters, 1860), Pygoderma bilabiatum (Wagner, 1843), Sturnira lilium, S. ludovici, Uroderma bilobatum, Uroderma sp. (Phyllostomidae); Molossops planirostris (Peters, 1865) e M. temminckii (Burmeister, 1854) (Molossidae).

Distribuição geográfica. México, El Salvador, Costa Rica, Panamá, Trinidad e Tobago, Venezuela, Colômbia, Brasil (Rondônia, Goiás, Distrito Federal, Minas Gerais, Rio de Janeiro, São Paulo, Paraná, Santa Catarina, Rio Grande do Sul), Peru, Bolívia e Argentina.

Material paranaense examinado. Arapoti: Fazenda Barra Mansa, 2 machos e 2 fêmeas em Pygoderma bilabiatum, Miretzki, Straub \& Bernils leg., 15/VII/1991 (MHNCI); 1 macho e 1 fêmeas em P. bilabiatum, Miretzki, Straub \& Bernils leg., 15/VII/1991 (MHNCI); Curitiba: 2 machos, hospedeiro indeterminado, C. Jaletebe leg., VIII/1946; Vila Hauer, Bosque Reinhard Maack, 1 macho em Sturnira lilium, 07/VII/1991 (MHNCI); Centro Politécnico, 1 fềmea em Artibeus lituratus, Cárceres \& Moura leg., 21/V/1997; Bom Retiro, 1 macho e 1 fềmea em A. lituratus, 10/III/1998 (MHNCI); Londrina: Parque Arthur Thomas, 6 machos, 5 fêmeas e 1? em A. lituratus, Graciolli \& Lima leg., 22/VIII/1998; Fundo de Vale do Quebec, 11 machos e 5 fêmeas em A. lituratus Graciolli \& Lima leg., 23/VIII/1998; Parque Arthur Thomas, 8 machos e 2 fêmeas em A. lituratus, Graciolli \& Lima leg., 12/IX/1998; Fundo de Vale do Quebec, 2 machos e 2 fêmeas em A. lituratus, Graciolli \& Lima leg., 13/IX/1998; Matinhos: Sertãozinho, Morro da Cruz, 1 fềmea em Artibeus fimbriatus, 03/VIII/1991 (MHNCI); 1 macho em S. lilium, 15/VII/1991 (MHNCI); Parque Nacional do Iguaçu: 4 machos e 1 fêmea em A. lituratus, Graciolli, Lima \& Rocha leg., 13///1999; 4 machos e 1 fềmea em A. lituratus, Graciolli, Lima \& Rocha leg., 11/I/1999; 1 macho e 1 fềmea em A. lituratus, Graciolli \& Rocha leg., 11/III/1999; 2 fêmeas em A. lituratus, Graciolli \& Rocha leg., 13/III/1999.

Comentário. Um macho foi coletado no Parque Nacional do Iguaçu com uma veia $\mathrm{r}-\mathrm{m}$ adicional, formando uma célula fechada, e uma fêmea coletada em Londrina possuía seis setas no escutelo. Variações no número de setas escutelares e na venação foram anteriormente observadas por ZEVE \& HOWELL (1963). Estes autores estudaram a morfologia externa do tórax de Trichobius corynorhini Cockerell, 1910, Trichobius major Coquillett, 1899 e Trichobius sphaeronotus Jobling, 1939 e verificaram que essas variações são muito comuns em T. major. Paratrichobius longicrus parasita principalmente morcegos do gênero Artibeus Gray, 1838, táxon que apresenta muita dificuldade na identificação das espécies. Provavelmente, em muitos registros o hospedeiro foi identificado erroneamente, sobretudo, no complexo jamaicensis-fimbriatus-lituratus-obscurus. WENZEL et al. (1966), sepa- 
raram populações de $P$. longicrus encontradas em vários hospedeiros, utilizando o comprimento do tórax, das asas e do fêmur em relação ao número de setas discais no esternito II. Consideraram $P$. longicrus parasito primário de $A$. lituratus, apesar do hospedeiro-tipo ser $A$. jamaicensis e os exemplares encontrados sobre outros hospedeiros (A. aztecus, A. jamaicensis, A. toltecus e Platyrrhinus vittatus) como pertencentes ao complexo longicrus. A interação entre Pygoderma bilabiatum e Paratrichobius longicrus é registrada pela primeira vez. GRACIOLLI \& RUI (2001) encontraram $P$. longicrus sobre $A$. lituratus e $A$. fimbriatus no nordeste do Rio Grande do Sul.

\section{Megistopoda Macquart, 1852}

Megistopoda Macquart, 1852: 332; Kessel, 1925: 28 (diagnose); Maa, 1965: 385, Syn.: Pterellipsis; Wenzel et al., 1966: 540, Syn.: Pterellipsis (chave de identificação das espécies); Wenzel, 1976: 98 (diagnose); Guerrero, 1994b: 185 (diagnose).

Pterellipsis Coquillett, 1899: 333; Kessel, 1925: 25 (diagnose); Machado-Allison, 1966: 70 (diagnose e chave de identificação das espécies).

Espécie-tipo de Megistopoda: Megistopoda pilatei Macquart, 1852, por monotipia.

Espécie-tipo de Pterellipsis: Pterellipsis aranea Coquillet, 1899, por designação original.

Diagnose. Corpo mais aplanado lateral que dorsoventralmente. Cabeça: arredondada, com o extremo posterior estreitado, em forma de funil. Lóbulos occipitais pouco esclerotinizados, visíveis só pelo grupo de setas que possuem. Olhos grandes, com seis a 12 facetas, e ligeiramente salientes aos lados da cabeça. Palpos arredondados a ovais, com setas marginais e longas no lado ventral. Tórax: mais alto do que amplo, com o bordo anterior projetado no centro, arredondado, dando um aspecto ovalado, igual na face ventral, a qual é ovalada com o extremo amplamente arredondado. Sutura mediana desenvolvida, reta e unida à transversal, que é completa. Braquípteros com asas estreitas com as veias reduzidas, quatro a seis longitudinais e três a quatro transversais. Pernas: posteriores muito mais longas que as anteriores e as medianas, com os fêmures posteriores o dobro dos medianos; tíbias quase tão longas quanto os fêmures e ligeiramente curvas. Fêmures de todas as pernas com uma a duas filas dorsais de macrosetas conspícuas. Abdômen: conetivo coberto de setas relativamente curtas e mais ou menos robustas. Esternito II subquadrado, com um grupo de setas marginais e outro triangular, na linha média, de setas mais grossas espiniformes.

Fêmea. Abdômen: Tergito VII pequeno, transverso e parcialmente unido à epiprocto no centro.

Macho. Abdômen: Esternito $\mathrm{V}$ amplo, com muitas setas marginais muito longas; esternito VI filiforme; sintergosternito VII+VIII e tergito IX bem individualizados. Gonópodos delicados, pouco curvados ventralmente, com setas acessórias com inserção distal à macroseta.

Comentário. Atualmente, este gênero conta com apenas duas espécies válidas, Megistopoda aranea (Coquillett, 1899) e M. proxima (Séguy, 1926). Ambas parasitam Stenodermatinae e são encontradas em quase toda Região Neotropical (GUERRERO 1994b). 


\section{Megistopoda aranea (Coquillett, 1899) nomen protectum}

Fig. 8

Megistopoda pilatei Macquart, 1852: 333, localidade-tipo: Teapa, México, Wenzel, 1970: 9. Nomen oblitum (ICZN, art. 23.9.2).

Pterellipsis aranea Coquillett, 1899: 334, localidade-tipo: Jamaica; Speiser, 1900b: 154, Syn.: desiderata; Jobling, 1949a: 327, Syn.: proxima; Machado-Allison, 1966: 70 (diagnose).

Megistopoda desiderata Speiser, 1900a: 57, localidade-tipo: Brasil, Cuba.

Megistopoda aranea; Wenzel et al., 1966: 541, 542, Syn.: pilatei; Wenzel, 1976: 98, Syn.: pilatei (diagnose); Guerrero, 1994b: 186 (diagnose); Autino et al., 1999: 133 (redescrição). Nomen protectum (ICZN, Art. 23.9.2).

Diagnose. Cabeça: laterovértice com cinco macrosetas e lóbulo occipital com quatro macrosetas. Olho composto com seis ou 12 facetas. Cabeça deslocada dorsalmente sobre o tórax, semelhante à Nycteribiidae. Tórax: anguloso mais alto do que largo. Mesonoto reduzido e convexo. Escuto com cinco a seis setas discais e quatro antescutelares. Escutelo com duas macrosetas. Esterno achatado em forma de prancha, parte anterior dobrada dorsalmente, ultrapassando as procoxas. Asas: reduzidas e estreitas, com quatro veias longitudinais; largura e comprimento variáveis. Macrosetas encobrindo toda a extensão das veias e bordas das asas. Pernas: metafêmur visivelmente mais longo que o comprimento do corpo. Abdômen: esternito II com duas setas espiniformes e duas setas um pouco mais finas na margem lateral. Conetivo abdominal com setas dorsais mais longas e largas que as demais do conetivo; face ventral com quatro filas de quatro setas, mais longas que as outras setas.

Fêmea. Abdômen: Tergito VII semelhante ao de P. longicrus. Epiprocto com duas setas laterais as macrosetas distais. A seta mais externa com metade do tamanho da anterior. Esternito II com seis setas espiniformes em dois grupos de três setas. Esternito VII dividido em dois escleritos ovais com 10 a 12 setas em cada um, cinco delas, macrosetas na margem posterior.

Macho. Abdômen: Esternito V retangular com 11 a 12 setas, sendo seis mais longas que o tergito. Sintergosternito VII+VIII com três setas de cada lado. Tergito IX com três setas dorsais e oito laterais. Gonópodos assimétricos, macroseta do gonópodo esquerdo localizada mais proximal do que no direito; seta acessória inserida posteriormente à macroseta; presença de uma fila irregular de setas espiniformes entre a seta acessória e o ápice (Fig. 8).

Hospedeiro-tipo. Indeterminado. Outros hospedeiros: Noctilio leporinus (Noctilionidae); Artibeus cinereus, A. fimbriatus, A. jamaicensis, A. lituratus, A. obscurus, A. planirostris (Spix, 1823), Carollia perspicillata, Chiroderma villosum, Desmodus rotundus, Diphylla ecaudata, Glossophaga longirostris Miller, 1898, Lonchorhina aurita, Phylloderma stenops Peters, 1865, Phyllostomus discolor, P. hastatus, Phyllostomus sp., Platyrrhinus lineatus, P. vittatus, Sturnira lilium, S. ludovici, Uroderma bilobatum e Vampyressa bidens (Dobson, 1878) (Phyllostomidae).

Distribuição geográfica. México, Cuba, Guatemala, Porto Rico, Jamaica, Antilhas Menores, El Salvador, Costa Rica, Panamá, Trinidad e Tobago, Venezuela, Colômbia, Guiana, Suriname, Brasil (Pará, Rondônia, Minas Gerais, Rio de Janeiro, São Paulo, Paraná, Santa Catarina, Rio Grande do Sul), Peru, Bolívia e Paraguai, Argentina. 
Material paranaense examinado. Parque Nacional do Iguaçu: 2 machos em Artibeus fimbriatus, Graciolli, Lima \& Rocha leg., 11/I/1999; 2 machos e 1 fêmea em A. fimbriatus, Graciolli, Lima \& Rocha leg., 12/I/1999; 1 fêmea em A. fimbriatus, Graciolli, Lima \& Rocha leg., 14/I/1999.

Comentário. GRACIOLLI \& RUI (2001) encontraram no estado do Rio Grande do Sul, M. aranea parasitando principalmente A. fimbriatus. Provavelmente em áreas onde ocorram apenas $A$. fimbriatus e A. lituratus, $M$. aranea seja encontrada preferencialmente sobre o primeiro hospedeiro citado.

\section{Megistopoda proxima (Séguy, 1926)}

Fig. 9

Pterellipsis proxima Séguy, 1926: 194, localidade-tipo: Arredores de San Ignacio, Vila Lutecia, Misiones, Argentina; Jobling, 1952: 134; Machado-Allison, 1966: 74 (diagnose).

Megistopoda proximum [sic]; Maa, 1965: 385.

Megistopoda proxima; Wenzel et al., 1966: 543; Wenzel, 1976: 99, Syn.: theodori (diagnose); Guerrero, 1994b: 187 (diagnose); Autino et al., 1999: 135 (redescrição).

Megistopoda theodori Wenzel, 1966 in Wenzel et al.: 545, localidade-tipo: Casa Tilley, Cerro Punta, Chiriqui, Panamá.

Diagnose. Cabeça: cônica. Laterovértice com seis macrosetas e lóbulo occipital com cinco a seis setas. Olho composto com oito a 11 facetas. Tórax: mesonoto pequeno e convexo, coberto por macrosetas. Sutura longitudinal além da sutura transversal. Prescuto com cerca de 22 setas; escuto com seis e quatro antescutelares. Escutelo com quatro macrosetas. Esterno em forma de prancha com a margem anterior dobrada dorsalmente. Lóbulo metasternal pequeno. Perna: metafêmur longo, menor que o comprimento do corpo. Abdômen: conetivo abdominal totalmente setoso, com quatro filas longitudinais paralelas de quatro setas, mais longas do que as outras do conetivo. Esternito II com setas discais espiniformes, margem posterior, oito setas espiniformes divididas em dois grupos.

Fêmea. Abdômen: Tergito VII pequeno, semelhante ao de Paratrichobius longicrus, com quatro setas, um par de outras menores entre um par de macrosetas. Epiprocto com quatro macrosetas distais, o par central mais fino e curto que o lateral, e duas setas pequenas em cada margem lateral. Esternito VII dividido em dois escleritos ovais com 10 a 12 setas em cada e cinco macrosetas na margem posterior.

Macho. Abdômen: Esternito V presente. Sintergosternito VII+VIII com três setas de cada lado. Tergito IX com nove a 10 setas. Gonópodo esquerdo com a posição mais proximal da macroseta; fila de setas espiniformes entre a seta acessória e o ápice e uma seta espiniforme na margem dorsal (Fig. 9).

Hospedeiro-tipo. Indeterminado. Outros hospedeiros: Noctilio leporinus (Noctilionidae); Pteronotus parnellii (Mormoopidae); Artibeus jamaicensis, A. lituratus, A. obscurus, Carollia perspicillata, Chiroderma villosum, Desmodus rotundus, Leptonycteris curosoae Miller, 1900, Lonchorhina aurita, Philloderma stenops, Phyllostomus discolor, P. hastatus, Platyrrhinus dorsalis, P. helleri, Sturnira bidens Thomas, 1915, S. bogotensis Shamel, 1927, S. erythromos, S. lilium, S. ludovici, S. tildae, Uroderma bilobatum, U. magnirostrum Davis, 1968 (Phyllostomidae). 
Distribuição geográfica. México, Cuba, Dominica, Martinica, Costa Rica, Panamá, Venezuela, Colômbia, Guiana Francesa, Brasil (Pará, Distrito Federal, Minas Gerais, Rio de Janeiro, Paraná, Santa Catarina, Rio Grande do Sul), Peru, Bolívia, Paraguai, Argentina e Uruguai.

Material paranaense examinado. Curitiba: 1 fêmea em "Um morcego pequeno", Centro Politécnico, 05/VI/1980 (DZUP); Londrina: Parque Arthur Thomas, 1 macho e 8 fêmeas em S. lilium, Graciolli \& Lima leg., 22/VIII/1998; Parque Nacional do Iguaçu: 3 machos e 1 fêmea em S. lilium, Graciolli, Lima \& Rocha leg., 11/I/1999; 1 fêmea em Artibeus lituratus, Graciolli, Lima \& Rocha leg., 12/I/1999; 1 macho em S. lilium, Graciolli, Lima \& Rochaleg., 12/I/1999; 2 fềmeas encontradas nas luvas do coletor, Graciolli \& Lima leg., 13/I/1999; 2 fềmeas em S. lilium, Graciolli, Lima \& Rocha leg., 13/I/1999; 1 macho em S. lilium, Graciolli, Lima \& Rocha leg., 14/I/1999; 4 machos e 1 fêmea em S. lilium, Graciolli \& Rocha leg., 11/III/1999; 3 machos e 1 fềmea em S. lilium, Graciolli \& Rocha leg., 14/III/1999; Três Barras do Paraná: Reserva Guarani, 1 macho em Sturnira lilium, Cárceres \& Bernils leg., 28/V/1998; 1 macho em S. lilium, Cárceres \& Bernils leg., 30/V/1998.

Comentário. Megistopoda proxima é considerada parasito primário de morcegos do gênero Sturnira Gray, 1842. Durante as capturas realizadas no Parque Nacional do Iguaçu, foi observado que as fêmeas de $M$. proxima estavam muito ativas. Muitas vezes, quando indivíduos de S. lilium eram capturados nas redes de neblina e manipulados, fêmeas de $M$. proxima podiam ser vistas abandonando o hospedeiro e correndo pelas malhas das redes, ou então subindo para as mãos do coletor. Estas observações podem explicar, em parte, a ocorrência de M. proxima sobre Artibeus lituratus, e talvez sobre outros hospedeiros.

\section{Aspidoptera Coquillett, 1899}

Aspidoptera Coquillett, 1899: 334; Speiser, 1900b: 153, Syn.: Lepopteryx; Costa Lima, 1921: 21 (chave de identificação das espécies); Kessel, 1925: 25 (diagnose), 26 (chave de identificação das espécies); Jobling, 194€a: 135 (revisão taxonômica, diagnose, chave de identificação das espécies); Wenzel, 1976: 103 (chave de identificação das espécies); Guerrero, 1995b: 138, 141 (diagnose e chave de identificação das espécies).

Lepopteryx Speiser, 1900a: 53.

Espécie-tipo de Aspidoptera: Aspidoptera busckii Coquillett, 1899, por designação original. Espécie-tipo de Lepopteryx: Lipoptena phyllostomatis Perty, 1833, por designação original.

Diagnose. Cabeça: laterovértices e lóbulos occipitais bem diferenciados. Laterovértices sem suturas; lóbulos occipitais arredondados posteriormente, sem um lóbulo ou saliência posterior. Tórax: sutura mediana completa e unida com a transversal, formando um " $T$ " invertido. Mesosterno pouco projetado anteriormente e com os lados obliquos. Metasterno com um lóbulo mediano flexionado, não unido com o metepímero. Pernas: curtas e subiguais, com setas longas no lado dorsal. Asas: braquípteros, com a venação completa.

Fêmea. Abdômen: Tergito VII muito pouco esclerotinizado, com uma fila transversal de dois a cinco setas curtas. Epiprocto curto. Esternito VII pequeno.

Macho. Abdômen: Esternito V ausente. Esternito VI presente ou não. Gonópodos curvados ventralmente, com as setas inseridas na metade basal, posteriormente à macroseta. 
Comentário. Atualmente, três espécies são incluídas neste gênero e que parasitam Phyllostomidae, principalmente Stenodermatinae (GUERRERO 1995b). No Brasil, foram registradas Aspidoptera phyllostomatis (Perty, 1833) e A. falcata Wenzel, 1976 (GUERRERO 1997).

\section{Aspidoptera falcata Wenzel, 1976}

Fig. 10

Aspidoptera falcata Wenzel, 1976: 104, localidade-tipo: Los Venados, Caracas, Distrito Federal, Venezuela; Guerrero, 1995b: 140 (diagnose).

Diagnose. Cabeça: laterovértice com cinco macrosetas e lóbulo occipital com cerca de 10 setas. Olho composto pequeno e elíptico, com seis a sete facetas. Tórax: Porção superior do mesepisterno com três filas de setas, iguais ou um pouco mais longas que as do prescuto, em vista dorsal. Escutelo com quatro macrosetas.

Fêmea. Abdômen: Tergito VII pequeno e pouco esclerotinizado com duas a cinco setas, geralmente quatro. Epiprocto com seis macrosetas distais e duas setas menores anterolaterais. Esternito VII dividido em dois escleritos com 11 setas em cada um.

Macho. Abdômen: Esternito VI presente. Sintergosternito VII+VIII com quatro setas e uma bem menor que as outras de cada lado. Tergito IX com mais ou menos 30 setas. Gonópodos falciformes; inserção da seta acessória anterior à macroseta (Fig. 10).

Hospedeiro-tipo. Sturnira lilium (Phyllostomidae). Outros hospedeiros: Artibeus cinereus, A. jamaicensis, A. obscurus, Carollia perspicillata, Desmodus rotundus, Phyllostomus hastatus, Platyrrhinus dorsalis, Sphaeronycteris toxophyllum, Sturnira ludovici, S. tildae, Uroderma bilobatum e Vampyressa pussila (Wagner, 1843) (Phyllostomidae).

Distribuição geográfica. Dominica, Venezuela, Brasil (Pará, Minas Gerais, Paraná), Peru, Bolívia e Paraguai.

Material paranaense examinado. Parque Nacional do Iguaçu: 2 fềmeas em Sturnira lilium, Graciolli, Lima \& Rocha leg., 14/X/1998; 2 machos e 1 fềmea em S. lilium, Graciolli, Lima \& Rocha leg., 14/I/1999; 4 machos e 2 fêmeas em S. lilium, Graciolli, Lima \& Rocha leg., 12/I/1999; 7 machos e 7 fềmeas em S. lilium, Graciolli, Lima \& Rocha leg., 11/I/1999; 1 macho e 1 fêmea em S. lilium, Graciolli, Lima \& Rocha leg., 13///1999; 3 machos, 2 fêmeas e 1 ? em S. lilium, Graciolli \& Rocha leg., 11/III/1999; 1 fêmea em S. lilium, Graciolli \& Rocha leg., 12/III/1999; 1 macho e 1 fêmea em S. lilium, Graciolli \& Rocha leg., 13/III/1999.

Comentário. WENZEL et al. (1966: 553 e 555) citaram a ocorrência de uma espécie não descrita de Aspidoptera muito semelhante à Aspidoptera delatorrei Wenzel, 1966 coletada em Teresópolis, Rio de Janeiro sobre S. lilium, possivelmente trata-se A. falcata. Na Argentina, BARQUEZ et al. (1991) e AUTINO et al. (1992, 1998, 1999) encontraram apenas Aspidoptera phyllostomatis, parasitando espécies de Sturnira, ao invés de $A$. falcata, parasita típico de Sturnira. KOMENo \& LINHARES (1999) trabalhando na Reserva Nacional do Panga, Minas Gerais também encontraram A. falcata e Megistopoda proxima sobre S. lilium. No presente trabalho, 
encontrou-se exemplares de S. lilium parasitados por A. falcata, apenas no Parque Nacional Iguaçu. Em Londrina, onde foram capturados indivíduos de S. lilizum foram coletados apenas especimens de Megistopoda proxima.

\section{Aspidoptera phyllostomatis (Perty, 1833)}

Fig. 11

Lipoptena phyllostomatis Perty, 1833: 190; Kolenati, 1863: 163 (transferência para Streblidae).

Aspidoptera busckii Coquillett, 1899: 335, localidade-tipo: Bayamon, Porto Rico; Coquillett, 1907: 291; Wenzel et al., 1966: 555.

Lepopteryx phyllostomatis; Speiser, 1900a: 53.

Aspidoptera phyllostomatis; Speiser, 1900b: 153, 154, Syn.: busckii; Jobling, 1949a: 135, 137, Syn.: busckii (redescrição); Wenzel et al., 1966: 553, localidade-tipo: Neótipo, exemplar de Hansa Humboldt [Corupá], Santa Catarina, Brasil Bgt.; Wenzel, 1976: 108, Syn.: busckii; Guerrero, 1995b: 138 (diagnose); Autino et al., 1999: 131 (redescrição).

Diagnose. Cabeça: laterovértice com cinco macrosetas e lóbulo occipital com 11. Olho composto com 10 facetas. Mesepisterno com uma fila de setas do mesmo tamanho ou maior que as do prescuto. Escutelo com quatro macrosetas.

Fêmea. Abdômen: Lóbulo do Sintergito I+II com 11 macrosetas. Esternito VII dividido em dois escleritos com nove a 10 setas em cada um. Tergito VII pequeno, elíptico, pouco esclerotinizado, com três a quatro setas. Epiprocto com seis macrosetas distais e um par lateral.

Macho. Abdômen: Lóbulo do Sintergito I+II com 10 macrosetas. Esternito VI filiforme. Sintergosternito VII+VIII com cinco setas. Tergito IX com 19 a 21 setas de cada lado, distribuídas em duas filas transversais. Setas dorsais mais longas e largas, as demais diminuem no comprimento em direção à face ventral. Gonópodos assimétricos, curvados; inserção da seta acessória anterior à macroseta (Fig. 11).

Hospedeiro-tipo. Phyllostomus sp. (Phyllostomidae). Outros hospedeiros: Pteronotus parnelli (Mormoopidae); Anoura caudifer, A. geoffroyi, Artibeus fimbriatus, A. jamaicensis, A. lituratus, A. obscurus, Artibeus sp., Carollia perspicillata, Chiroderma villosum, Glossophaga soricina, Micronycteris schimidotum Sandborn, 1935, Phyllostomus discolor, P. hastatus, Sturnira erythromos, S. lilium, Uroderma bilobatum e Vampyressa nymphaea Thomas, 1909 (Phyllostomidae).

Distribuição geográfica. México, Cuba, Porto Rico, Guatemala, Costa Rica, Panamá, Trinidad, Venezuela, Colômbia, Brasil (Pará, Rondônia, Distrito Federal, Rio de Janeiro, Paraná, Santa Catarina), Peru, Bolívia, Paraguai e Argentina.

Material examinado. Parque Nacional do Iguaçu: 1 macho em Artibeus fimbriatus, Graciolli, Lima \& Rocha leg., 12/XI/1998; 1 macho e 2 fêmeas em $A$. fimbriatus, Graciolli, Lima \& Rocha leg., 11/I/1999; 1 macho e 1 fêmea em $A$. fimbriatus, Graciolli, Lima \& Rocha leg., 12/1/1999; 1 fêmea em Artibeus sp., Graciolli \& Rocha leg., 11/III/1999.

Comentário. Aspidoptera phyllostomatis é normalmente encontrada sobre as espécies de Artibeus. No entanto, há registros dessa espécie sobre espécies do gênero Sturnira na Argentina (BARQUEZ et al. 1991; AUTINO et al. 1992, 1998, 1999). 


\section{Exastinion Wenzel, 1966}

Exastinion Wenzel, 1966 in Wenzel et al.: 558; Wenzel, 1976: 108 (chave de identificação das espécies); Guerrero, 1995b: 141 (diagnose e chave de identificação das espécies).

Espécie-tipo: Aspidoptera clovisi Pessôa \& Guimarães, 1936, por designação original.

Diagnose. Cabeça: aplanada. Premento cordiforme. Palpos ovalados, ligeiramente mais longos que amplos, a margem anterior obliquamente truncada, com setas ao longo da margem e com a metade basal ventral coberta de setas finas e o lado dorsal coberto de microsetas. Laterovértice e lóbulos occipitais bem diferenciados, microsetosos, com as setas dos laterovértices restritas à porção anterolateral; lóbulos occipitais oblíquos, com à margem posterior pigmentada, trilobada, com setas largas e sobrepondo-se a margem anterior do prescuto; laterovértices com longo processo dirigido posteriormente. Olhos pequenos com uma ou cinco a seis facetas. Tórax: mesonoto plano; com a sutura mediana bifurcada anteriormente e unida posteriormente à sutura transversal sinuosa; escuto muito curto, menos de 1/3 do prescuto. Mesosterno amplamente emarginado e projetado entre as coxas. Lóbulo metasternal arredondado e ligeiramente flexionado. Asas: braquípteros, com as veias bem desenvolvidas, sem a segunda e a terceira transversais. Pernas: curtas, subiguais, com os fêmures curtos e robustos. Abdômen: conetivo dorsal sem setas, exceto nos lados, e sem setas segmentadas pareadas no dorso; lados e ventre com setas finas e curtas. Sintergito I+II muito curto no centro e com lóbulos laterais conspícuos. Esternito II bem desenvolvido, setoso em uma área triangular mediana e ao longo do bordo posterior, com as setas nascendo em uma pequena placa translúcida.

Fêmea. Abdômen: Tergito VII pequeno, translúcido, pouco esclerotinizado e transversal, com duas pequenas setas. Epiprocto muito curto, transversal. Esternito VII curto e transverso.

Macho. Abdômen: Esternito V curto e amplo; esternito VI indistinguível, representado por uma banda translúcida. Tergito IX muito curto; gonópodos como em Trichobius, com a seta acessória anterior à macroseta.

Comentário. Atualmente, o gênero é formado por três espécies que parasitam morcegos nectarívoros Anoura Gray, 1838 (GUERRERo 1995b). No Brasil, apenas Exastinion clovisi (Pessôa \& Guimarães, 1936) foi coletada (GuERrERo 1997).

\section{Exastinion clovisi (Pêssoa \& Guimarães, 1936)}

Fig. 12

Aspidoptera clovisi Pessôa \& Guimarães, 1936: 262, localidade-tipo: Ipiranga, São Paulo, São Paulo, Brasil; Jobling, 1949a: 138 (redescrição).

Exastinion clovisi; Wenzel et al., 1966: 560; Wenzel, 1976: 108 (diagnose); Guerrero, 1995b: 142 (diagnose).

Diagnose. Cabeça: arredondada em vista dorsal. Laterovértice com cinco macrosetas e duas setas pequenas na margem anterior. Lóbulo occipital expandido e trilobado posteriormente, com oito macrosetas. Olho unifacetado, grande e elíptico. Tórax: prescuto cerca de quatro vezes mais longo do que o escuto, com macrosetas em toda superfície, menos na área triangular anterior. Mesepisterno II com três a quatro filas de setas mais longas e largas que as do mesonoto, com 10 a 11 setas em vista 
dorsal. Prescuto com três filas longitudinais de setas de cada lado. Escuto com oito setas e escutelo com seis. Parte anterior do esternito com dois dentes expandidos entre as procoxas. Setação muito curta, dificil de perceber em álcool. Lóbulo metasternal subretangular e curvado dorsalmente. Abdômen: lóbulo do sintergito I+II com 35 setas. Conetivo abdominal ventral com duas filas transversais de quatro setas; sendo estas três vezes mais longas que as do conetivo lateral.

Fêmea. Abdômen: Margens póstero-laterais com um tufo ou conjunto de setas mais longas que as do esclerito. Esternito VII dividido em dois escleritos ao meio com 14 setas em cada um, algumas muito longas. Epiprocto com quatro macrosetas distais.

Macho. Abdômen: lóbulo lateral do Sintergito I+II com cerca de 14 setas. Esternito $\mathrm{V}$ com setas maiores na margem posterior. Sintergosternito VII+VIII pequeno em dois artículos com mais ou menos 10 setas. Tergito IX com cerca de 19 setas. Gonópodos altos e curvados, estreitado-se bruscamente na face ventral, após a macroseta (Fig. 12).

Hospedeiro-tipo. Anoura geoffroyi (Phyllostomidae). Outros hospedeiros: Peropteyx macrotis (Wagner, 1843) (Emballonuridae); Pteronotus parnelli (Mormoopidae); A. caudifer, A. latidens Handley, 1984, Anoura sp., Artibeus jamaicensis, Leptonycteris sp. e Sturnira lilium (Phyllostomidae).

Distribuição geográfica. México, Guatemala, Costa Rica, Panamá, Trinidad e Tobago, Venezuela e Brasil (Mato Grosso, Minas Gerais, São Paulo, Paraná, Rio Grande do Sul).

Material paranaense examinado. Curitiba: 1 fêmea em Anoura geoffroyi, 23/X/1998.

Material adicional examinado. BRASIL: Rio Grande do Sul, Dom Pedro de Alcântara, 2 machos e 4 fêmeas em Anoura geoffroyi, Graciolli \& Rui leg., 06/IX/1997 (DZUP).

Comentário. No sul do continente americano, Exastinion clovisi parasita somente Anoura geoffroyi, outros registros de hospedeiros são provavelmente acidentais ou errôneos.

\section{Noctiliostrebla Wenzel, 1966}

Noctiliostrebla Wenzel, 1966 in Wenzel et al.: 560; Wenzel, 1976: 113 (chave de identificação das espécies); Guerrero, 1995b: 147 (diagnose), 150 (chave de identificação das espécies).

Espécie-tipo: Lipoptena dubia Rudow, 1871, por designação original.

Diagnose. Cabeça: subarredondada em vista dorsal; os lóbulos occipitais e os laterovértices bem definidos, cada laterovértice dividido por uma sutura obscura oblíqua. Palpos irregulares arredondados, com setas marginais e superfície ventral sem setas. Premento subcodiforme. Tórax: margem anterior do prescuto pouco emarginada, ligeiramente projetada no centro; sutura mediana forte, completa e unida com a transversal formando um "Y" invertido. Aberturas espiraculares grandes e muito conspícuas. Prescuto sem setas discais, setas restritas aos lados e à margem anterior. Superfícies dorsal e ventral do tórax com áreas claras conspícuas na cutícula. Asas: muito curtas, ovais, pontiagudas, com setas marginais e veias 
indistintas, reduzidas em número, geralmente três ou quatro. Pernas: curtas, subiguais, setas das tíbias ralas, dispostas em filas. Tarsos robustos, medindo cerca de 3/4 das tíbias; tarsômeros 1 a 4 compridos? antero-posteriormente, o último com lados subparalelos, tão longo quanto os quatros anteriores combinados. Garras tarsais muito grandes. Abdômen: espiráculos muito menores que os torácicos, porém conspícuos e inflados. Conetivo abdominal transversalmente enrugado, as setas curtas e inseridas em placas pouco esclerotinizadas. Sintergito I+II bem desenvolvido.

Fêmea. Abdômen: Tergito VII representado por um par de escleritos transversais. Epiprocto curto.

Macho. Abdômen: Tergito IX bem desenvolvido e saliente. Esternitos V e VI ausentes. Gonópodos curtos, livres e separados, não se unindo a sua coberta, articulados ao apódema gonapofiseal e, posteriormente, à base curvada do edeago, o qual é fortemente comprimido lateralmente e em forma de espada em vista lateral e posteriormente curvado, porém não enrolado.

Comentário. Este gênero abriga quatro espécies (GUERRERo 1995b). No Brasil, foram coletadas Noctiliostrebla aitkeni Wenzel, 1966, N. dubia (Rudow, 1871) e N. maai Wenzel, 1966 (GUERRERo 1997). WENZEL et al. (1966: 563) citam ter examinado uma espécie não descrita proveniente do Brasil. Parasitam morcegos ictiófagos Noctilio Linnaeus, 1766 (Noctilionidae). As espécies do gênero são morfologicamente muito homogêneas e de difícil identificação sem a comparação com material previamente identificado. Um mesmo hospedeiro pode abrigar simpatricamente mais de uma espécie de Noctiliostrebla (WENZEL 1976).

\section{Noctiliostrebla aitkeni Wenzel, 1966}

Fig. 13

Aspidoptera megastigma; Jobling, 1949a: 140 (redescrição). Erro de identificação.

Noctiliostrebla aitkeni Wenzel, 1966 in Wenzel et al: 567, localidade-tipo: Manzanilla, Trinidad; Guerrero, 1995b: 148 (diagnose).

Diagnose. Cabeça: laterovértice dividido por uma sutura pigmentada transversal, com cinco setas e uma macroseta convergente. Lóbulo occipital com cinco macrosetas distribuídas em duas filas transversais. Tórax: Prescuto duas vezes maior do que o escuto e com uma fila de setas atrás dos espiráculos e um par de setas anterior a eles. Escuto com oito setas alternadas em macrosetas e setas menores. Escutelo com duas macrosetas. Margem posterior do esterno fendido.

Fêmea. Abdômen: Conetivo abdominal, atrás do lóbulo do sintergito I+II, com um grupo de 15 setas em volta do terceiro espiráculo, setas mais longas e largas que as outras do conetivo abdominal, seguido de uma faixa de setas um pouco finas e curtas até o sétimo espiráculo. Área mais esclerotinizada abaixo do grupo de 15 setas. Conetivo abdominal lateral com setas pequenas. Tergito VII desenvolvido, esclerotinizado com sete setas em cada tergito. Epiprocto com quatro macrosetas distais e uma fila anterior de setas menores. Conetivo abdominal dorsal com áreas sem setas. Esternito VII dividido em dois esternitos com nove setas em cada um, três delas maiores que as outras. 
Macho. Abdômen: Tergito IX desenvolvido, coberto por setas um pouco mais longas que as do conetivo abdominal; o processo ventral aplanado na extremidade distal. Gonópodos com inserção da seta acessória anterior à macroseta; edeago com espinho dorsal (Fig. 13).

Hospedeiro-tipo. Noctilio leporinus (Noctilionidae). Outro hospedeiro: Saccopteryx bilineata (Emballonuridae).

Distribuição geográfica. Ilhas Monos, Trinidad e Tobago, Venezuela, Suriname, Brasil (Pará, Minas Gerais, Paraná), Peru e Argentina.

Material paranaense examinado (todo material coletado em Noctilio leporinus). Guaraqueçaba: 7 machos e 5 fềmeas, Bordignon leg., 16/IV/1998; 38 machos e 23 fêmeas, Bordignon leg., 19/V/1998; 12 machos e 11 fềmeas, Bordignon leg., 17/VI/1998; Londrina: 9 machos e 5 fềmeas, Lima, leg., 22/XI/1998; Matinhos: Caiobá, 29 machos e 33 fêmeas, Bordignon leg., 09/I/1998; 38 machos e 33 fềmeas, idem leg., 12/II/1998; 2 machose 1 fềmea, idem leg., 13/II/1998; 31 machos e 26 fềmeas, idem leg., 17/II/1998; 3 macho e 2 fêmeas, idem leg., 06/IV/1998; 12 machos e 15 fêmeas, idem leg., 08/IV/1998; 9 machos e 9 fềmeas, idem leg., 09/IV/1998; 12 machos e 7 fềmeas, idem leg., 10/IV/1998; 37 machos e 19 fềmeas, idem leg., 22/IV/1998; 26 machos e 18 fềmeas, idem leg., 23/IV/1998; 14 machos e 12 fêmeas, idem leg., 02/VI/1998; 2 machos e 1 fêmeas, idem leg., 30/VI/1998; 5 machos e 3 fềmeas, idem leg., 01/VII/1998; 1 machos e 1 fềmeas, idem leg., 19/IX/1999; 43 machos e 43 fêmeas, idem leg., 20/I/1999; 6 machos e 3 fêmeas, idem leg., 21/I/1999; 9 machos e 8 fêmeas, idem leg., 10/II/1999; 39 machos e 40 fêmeas, idem leg., 11/II/1999; 8 machos e 4 fềmeas, idem leg., 12/II/1999; 2 machos e 1 fêmeas, idem leg., 16/III/1999; 31 machos e 24 fềmeas, idem leg., 17/III/1999; 4 machos e 4 fêmeas, idem leg., 18/III/1999; 8 machos e 6 fềmeas, idem leg., 19/VI/1999; 25 machos e 20 fêmeas, idem leg., 20/VI/1999.

Material adicional examinado. PERU, Loreto: Maynas, Rio Youri-Mirim, Quebrada Esperanza, 1 macho e 1 fềmea (Parátipos) em Noctilio leporinus, Ralinouski, leg. 23/IX/1957 (MZSP).

Comentário. Espécie muito semelhante à Noctiliostrebla maai, que parasita Noctilio albiventris, e parece estar restrita à América do Sul. No Paraná, foi encontrada simpatricamente com Paradyschiria fusca Speiser, 1900 sobre o mesmo hospedeiro.

\section{Paradyschiria Speiser, 1900}

Paradyschiria Speiser, 1900a: 55; Kessel, 1925: 26 (diagnose), 27 (chave de identificação das espécies); Wenzel et al., 1966: 571 (chave de identificação das espécies); Wenzel, 1976: 117 (chave de identificação das espécies); Guerrero, 1995b: 150 (diagnose), 154 (chave de identificação das espécies).

Espécie-tipo: Paradyschiria fusca Speiser, 1900, por designação original.

Diagnose. Cabeça: arredondada, com os lóbulos occipitais e os laterovértices bem esclerotinizados e distintos, marcados por um grupo de setas longas. Olhos grandes unifacetados. Palpos arredondados a ovais, com setas na margem. Tórax: muito modificado, com o prescuto retangular, mais longo que amplo e dividido em dois pela sutura mediana, esta reta chegando à metade do mesonoto; escutelo 
formado por uma pequena placa triangular com duas macrosetas e o escuto, uma pequena zona que une o prescuto com o escutelo. A notopleura muito ampla, deixando amplas zonas sem esclerotinização. Espiráculos muito grandes, deslocados dorsalmente. Lado ventral normal. Asas ausentes. Pernas curtas e robustas, sem macrosetas conspícuas. Abdômen: totalmente coberto de setas inseridas em pequenas placas.

Fêmea. Abdômen: Tergito VII unido ao epiprocto, ambos bem esclerotinizados. Esternito VII pequeno.

Macho. Abdômen: Gonópodos relativamente curtos, com seta acessória e macroseta não diferenciadas. Edeago curto e dilatado.

Comentário. Atualmente este gênero, abriga cinco espécies (GUERRERO 1995b). Como Noctiliostrebla, parasitam morcegos ictiófagos (Noctilionidae) e podem ser encontradas simpatricamente sobre o mesmo hospedeiro, Paradyschiria fusca e $P$. lineata Kessel, 1925 parasitam Noctilio leporinus e as espécies restantes parasitam $N$. albiventris. Paradyschiria é formado por espécies morfologicamente muito semelhantes, de difícil identificação sem material previamente identificado. Alguns autores suspeitam que algumas destas espécies seriam apenas variações clinais de uma mesma espécie (WENZEL 1976; GUERRERO 1995b).

\section{Paradyschiria fusca Speiser, 1900}

\section{Fig. 14}

Paradyschiria fusca Speiser, 1900a: 56, localidade-tipo: Orocué, Colômbia; Guerrero, 1995b: 151 (diagnose); Autino et al., 1999: 136 (redescrição).

Paradyschiria dubia; Kessel, 1925: 27 (diagnose); Guimarães, 1941: 217 (redescrição). Erro de identificação.

Diagnose. Cabeça: laterovértice com cinco setas. Lóbulo occipital com quatro macrosetas. Tórax: seta acessória ao lado da macroseta posterior do prescuto ausente. Abdômen: setas ventrais mais curtas que as outras, exceção de duas a quatro filas irregulares de setas na parte posterior do abdômen, tão longas quanto as laterais e dorsais.

Fêmea. Abdômen: Sintergito I+II com duas a três setas mais longas que o próprio esclerito na margem posterior. Entre o sintergito I+II e o terceiro espiráculo abdominal uma área lateral esclerotinizada. Epiprocto com quatro macrosetas distais, duas setas laterais e duas discais. Esternito VII dividido em dois escleritos, cada um com seis setas longas na margem posterior e nove setas anteriores mais curtas.

Macho. Abdômen: Esternito V dividido em dois pequenos escleritos elípticos com seis a sete setas cada. Tergito IX grande e ovalado, coberto de setas. Gonópodos retilíneos com uma fila lateral de pequenas setas (Fig. 14).

Hospedeiro-tipo. Noctilio leporinus (Noctilionidae). Outros hospedeiros: Noctilio albiventris (Noctilionidae); Anoura geoffroyi, Artibeus lituratus e Glossophaga soricina (Phyllostomidae).

Distribuição geográfica. Trinidad e Tobago, Venezuela, Colômbia, Suriname, Guiana Francesa, Brasil (Pará, Bahia, Minas Gerais, Mato Grosso do Sul, São Paulo, Paraná, Rio Grande do Sul), Peru e Argentina. 
Material paranaense examinado (todos exemplares coletados sobre Noctilio leporinus). Guaraqueçaba: 4 machos e 4 fềmeas, Bordignon leg., 19/V/1998. 8 machos e 3 fềmeas, Bordignon leg., 17/VI/1999; Londrina: 20 machos e 14 fềmeas, Lima leg., 22/XI/1998; Matinhos: Caiobá, 28 machos e 18 fêmeas, Bordignon leg., 09/I/1998; 10 machos e 9 fềmeas, idem leg., 12/II/1998; 2 machos e 3 fềmeas, idem !eg., 13/II/1998; 13 machos e 9 fêmeas, idem leg., 17/II/1998; 1 machos e 1 fềmeas, idem leg., 08/IV/1998; 1 machos e 3 fêmeas, idem leg., 09/IV/1998; 14 machos e 11 fềmeas, idem leg., 10/IV/1998; 34 machos e 28 fềmeas, idem leg., 22/V/1998; 16 machos e 7 fêmeas, idem leg., 23/V/1998; 9 machos e 14 fềmeas, idem leg., 02/VI/1998; 11 machos e 21 fềmeas, idem leg., 30/VI/1998; 8 machos e 8 fềmeas, idem leg., 01/VII/1998; 21 machos e 18 fềmeas, idem leg., 19/IX/1998; 15 machos e 10 fêmeas, idem leg., 20/I/1999; 5 machos e 4 fêmeas, idem leg., 21/I/1999; 9 machos e 8 fêmeas, idem leg., 10/II/1999; 13 machos e 6 fềmeas, idem leg., 11/II/1999; 9 machos e 5 fêmeas, idem leg., 12/II/1999; 2 machos e 1 fêmeas, idem leg., 16/III/1999; 9 machos e 7 fêmeas, idem leg., 17/III/1999; 3 machos e 2 fêmeas, idem leg., 18/III/1999; 3 machos e 9 fêmeas, idem leg., 19/VI/1999; 20 machos e 14 fêmeas, idem leg., 20/VI/1999.

Material adicional examinado: BRASIL, Pará: Itaituba, Km 58 Transamazônica, 1 fềmea em Noctilio leporinus, S. A. Marques \& T. K. George leg. 4/I/1979 (MZSP).

Comentário. Wenzel (1976) comentou que $P$. fusca e $P$. lineata são espécies muito semelhantes e têm distribuição contínua. Supôs então que estas poderiam ser raças geográficas de uma mesma espécie. GUERRERO (1995b: 150) relatou que há grande dificuldade para a separação das espécies que apresentam variações clinais e que não foram estudadas profundamente. GUERRERO (1995b: 152) exemplificou esta dificuldade ao comentar que no material coletado na Venezuela encontrou exemplares com caracteres intermediários entre $P$. fusca e $P$. lineata.

\section{Paradyschiria parvula Falcoz, 1931}

Fig. 15

Paradyschiria parvula Falcoz, 1931: 267, localidade-tipo: Brasil; Wenzel et al, 1966: 575; Guerrero, 1995b: 152 (diagnose).

Paradyschiria dubia; Jobling, 1949b: 328, Syn.: parvula.

Diagnose. Cabeça: laterovértice com cinco setas e lóbulo occipital com seis setas. Tórax: mesonoto com uma pequena seta anterior e lateral à grande macroseta do ângulo póstero-lateral. Abdômen: sintergito I+II com duas setas espiniformes discais, próximas à margem posterior, em cada lado do esclerito.

Fêmea. Abdômen: Conetivo abdominal coberto de setas pustuladas. Setas pustuladas dorsais mais longas que as laterais e as ventrais. Epiprocto com quatro macrosetas distais e dois pares de setas menores anterolaterais às macrosetas distais. Esternito VII dividido em dois escleritos, cada um com seis setas longas na margem posterior e 11 setas anteriores mais curtas.

Macho. Abdômen: Conetivo abdominal com setação curta e muito densa dorsalmente; setas ventrais mais espaçadas e mais longas. Tergito $\mathrm{V}$ muito pequeno 
e pouco esclerotinizado, quase imperceptível em alguns exemplares; dividido em dois escleritos com sete setas em cada um. Tergito IX amplo, coberto de setas em toda superfície e com duas a três macrosetas. Gonópodos quase retilíneos, levemente curvados ventralmente, com um par de setas basais mais longas e largas, uma fila de setas ventrais e três setas dorsais (Fig. 15).

Hospedeiro-tipo. Noctilio albiventris (Noctilionidae). Outros hospedeiros: Rhynchonycteris naso (Emballonuridae); Noctilio sp. (Noctilionidae); Uroderma sp. (Phyllostomidae); Molossus ater e M. molossus (Molossidae).

Distribuição geográfica: Trinidad e Tobago, Venezuela, Colômbia, Brasil (Pará, Rondônia, Mato Grosso, São Paulo, Paraná), Peru e Bolívia.

Material paranaense examinado (todos exemplares coletados sobre Noctilio albiventris). Diamante do Norte: 25 machos e 10 fêmeas, 30/IX/1994; 1 macho e 1 fêmea, 27/X/1994; 7 machos e 6 fêmeas, 28/X/1994; 10 machos, 2 fêmeas e 3?, 18/XII/1994 (MHNCI).

Material adicional examinado. BRAsIL, São Paulo: Barueri, 2 machos e 1 fềmea, S.B. Pessôa leg. III/1926, Wenzel det. (MZSP).

Comentário. Até o momento, espécie com distribuição restrita à América do Sul, acompanhando a distribuição do hospedeiro primário (Noctilio albiventris).

\section{Strebla Wiedemann, 1824}

Strebla Wiedemann, 1824: 19; Wenzel et al., 1966: 590, 594, Syn: Euctenodes (chave de identificação das espécies); Wenzel, 1976: 135 (chave de identificação das espécies); Guerrero, 1996a: 1 (diagnose), 15 (chave de identificação das espécies).

Euctenodes Waterhouse, 1879: 310; Kessel, 1924: 409 (diagnose); 1925: 30 (diagnose, chave de identificação das espécies); Garcia \& Casal, 1965: 5 (diagnose), 11 (chave de identificação das espécies).

Espécie-tipo de Strebla: Hippobosca vespertilionis Fabricius, 1805, por monotipia.

Espécie-tipo de Euctenodes: Euctenodes mirabilis Waterhouse, 1879, por monotipia.

Diagnose. Cabeça: palpos fusionados à cabeça. Frontoclípeo e pós-vértice grandes e bem desenvolvidos, bem como a gena e a pós-gena. Ctenídio ocupando todo a porção ventral da cabeça e estendendo-se até a porção laterodorsal. Tórax: mesonoto totalmente coberto de setas, ainda que podem haver pequenas áreas, em especial acerca do bordo anterior do prescuto, sem setas e ocasionalmente com uma sutura pigmentada prescutal. Asas: grandes e totalmente desenvolvidas, venação e setação normais. Pernas: curtas e grossas, ainda que as posteriores um pouco mais largas que as medianas. Metatíbias com pelo menos com duas macrosetas conspícuas subapicais.

Comentário. WeNZEL et al. (1966) e WeNZEL (1976) realizaram os trabalhos mais importantes à respeito deste gênero. Nestes trabalhos foram descritas 19 espécies, cerca de $73 \%$ dos nomes válidos para o gênero. GUERRERO (1996a) reconheceu 24 nomes válidos e colocou três nomes em situação duvidosa. No Brasil, foram registradas onze espécies de Strebla (GUERRERo 1997). 


\section{Strebla chrotopteri Wenzel, 1976}

Fig. 16

Strebla chrotopteri Wenzel, 1976: 144, localidade-tipo: La Pastora, Miremire, Falcón, Venezuela; Guerrero, 1996a: 12 (diagnose).

Diagnose. Cabeça: frontoclípeo dividido em duas placas denteadas e pequenas anteriormente. Olho composto com nove facetas. Projeção anterior do pós-vértice arredondada ou pontiaguda. Occipício com três a quatro setas espiniformes. Tórax: sutura pigmentada visível. Fila de seta anterior à sutura pigmentada com setas mais longa do que as outras do prescuto. Quatro filas de setas transversais entre a sutura pigmentada e a sutura transversal. Perna: metatíbia com um par de setas subapicais dorsais mais longas que outras setas. Abdômen: Lóbulo do Sintergito I+II com 14 a 22 setas.

Fêmea. Abdômen: Setas laterais do conetivo abdominal mais longas que as outras setas do conetivo. Tergito VII desenvolvido, forma pentagonal em vista posterior, mais longo que largo. Um par de macrosetas posterolateral e um de setas menores entre elas, com ou sem uma seta acessória anterior ao par central. Epiprocto com quatro macrosetas distais e quatro setas discais menores anteriores, em duas filas. Esternito VII dividido em dois escleritos com 12 a 14 setas em cada um.

Macho. Abdômen: Esternito V retangular, com nove a dez setas na margem posterior, com o comprimento maior que o do tergito. Sintergosternito VII+VIII com uma macroseta e uma seta diminuta dorsalmente. Tergito IX com três setas dorsais, cinco látero-posteriores e cinco pequenas discais. Gonópodos longos levemente curvados, no ápice arredondados com pequena reentrância ventral; inserção da seta acessória posterior à macroseta (Fig. 16).

Hospedeiro-tipo. Chrotopterus auritus (Phyllostomidae). Outros hospedeiros: Chiroderma villosum e Phyllostomus discolor (Phyllostomidae).

Distribuição geográfica. Venezuela, Brasil (Distrito Federal, Paraná) e Bolívia.

Material paranaense examinado. Parque Nacional do Iguaçu: 2 machos e 3 fêmeas em Chrotopterus auritus, Graciolli, Lima \& Rocha leg., 12/I/1999; 4 machos e 4 fêmeas em C. auritus, Graciolli \& Rocha leg., 13/III/1999; 4 machos e 3 fềmeas em C. auritus, Graciolli \& Rocha leg., 14/III/1999.

Comentário. Parasito primário de Chrotopterus auritus em toda a sua distribuição geográfica.

\section{Strebla diaemi Wenzel, 1966}

Fig. 17

Strebla diaemi Wenzel, in Wenzel et al, 1966: 599, localidade-tipo: Armila, San Blas, Panamá; Guerrero, 1996a: 7 (diagnose).

Diagnose. Cabeça: frontoclípeo inteiro. Olho composto com sete facetas. Tórax: subquadrado, mesonoto com setas distribuídas uniformemente. Setas do prescuto um pouco maiores do que as do escuto. Uma fileira irregular de setas curtas e espiniforme na margem anterior do prescuto. Prescuto com comprimento de duas vezes o escuto. Pernas: metatíbia com sete setas maiores do que as outras, na face 


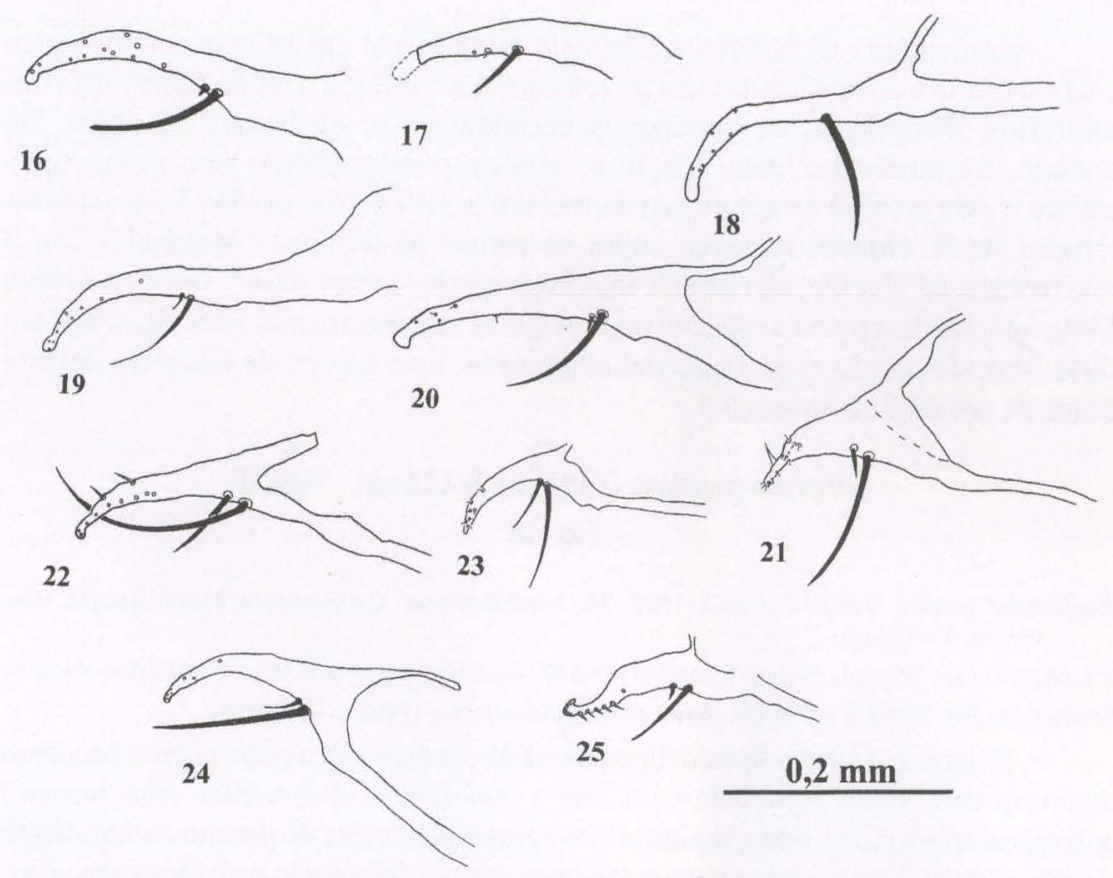

Figs 16-25. Gonópodos de Streblinae. (16) Strebla chrotopteri; (17) Strebla diaemi; (18) Strebla guajiro; (19) Strebla mirabilis; (20) Strebla wiedemanni; (21) Paraeuctenodes longipes; (22) Paraeuctenodes simili; (23) Anastrebla caudiferae; (24) Anastrebla modestini; (25) Metelasmus pseudopterus.

dorsal, dispostas em duas filas. Abdômen: lóbulo I+II com 21 setas. Setas laterais do conetivo abdominal mais largas que as outras.

Fêmea. Abdômen: Tergito VII pentagonal com um par de macrosetas e, entre estas, um par de setas menores. Epiprocto com quatro macrosetas distais e um par de setas laterais. Esternito VII dividido em dois escleritos com 12 a 15 setas em cada um.

Macho. Abdômen: Sintergosternito VII+VIII com um par de macrosetas. Gonópodos longos e levemente curvados; inserção da seta acessória posterior à macroseta (Fig. 17).

Hospedeiro-tipo: Diaemus youngii (Jentink, 1893) (Phyllostomidae). Outros hospedeiros: Diphylla ecaudata, Carollia perspicillata e Sturnira lilium (Phyllostomidae).

Distribuição geográfica. Panamá, Venezuela, Colômbia, Brasil (Pará, São Paulo, Paraná), Peru e Bolívia.

Material paranaense examinado. Cerro Azul: 2 machos em Diaemus youngii, Viana leg., 11/III/1983 (DZUP).

Material adicional examinado. BRASIL, São Paulo: Itabira, 1 macho e 1 fềmea em Carollia perspicillata, Garbe leg., sem data, Wenzel det. (MZSP). 
Comentário. O material examinado foi montado em alfinete entomológico e se encontrava em estado de conservação que não permitia a nítida observação dos escleritos abdominais; os gonópodos encontravam-se quebrados no ápice. No entanto, foi possível a identificação da espécie principalmente pelo frontoclípeo inteiro e pela setação característica da metatíbia. GUERRERO (1996: 7), na caracterização de $S$. diaemi, escreveu sobre as pernas posteriores: "Metatíbias con 7 macrosetas, en una fila, claramente más larga que las outras setas". WENZEL (1966: 599), quando descreveu a espécie, relatou que as sete macrosetas estão dispostas em duas filas, de acordo com o material examinado. Este engano de Guerrero deve se tratar de um erro de impressão.

\section{Strebla guajiro (Garcia \& Casal, 1965)}

Fig. 18

Euctenodes guajiro García \& Casal, 1965: 14, localidade-tipo: Campamento Rafael Rangel, Edo. Aragua, Venezuela.

Strebla carolliae Wenzel, 1966 in Wenzel et al.: 619, localidade-tipo: Fort Davis, Canal Zone, Panamá. Strebla guajiro; Wenzel, 1976: 151, Syn.: carolliae; Guerrero, 1996a: 5 (diagnose).

Diagnose. Cabeça: frontoclípeo dividido em duas placas denteadas e pequenas anteriormente. Olho composto com seis a oito facetas. Pós-vértice com margem anterior ampla e plana. Setas espiniformes aproximadamente do mesmo comprimento do pós-vértice. Tórax: sutura pigmentada bem visível. Mesonoto com áreas sem setas. Prescuto duas a duas vezes e meia mais longo que o escuto. Pernas: tíbia posterior com duas setas subapicais maiores do que as outras na face dorsal. Abdômen: setas laterais do conetivo abdominal mais longas e largas que as outras do conetivo.

Fêmea. Abdômen: Tergito VII com duas macrosetas e duas setas posteriores com metade do comprimento. Epiprocto com quatro macrosetas distais. Esternito VII dividido em dois escleritos com cerca de 12 setas em cada um.

Macho. Abdômen: Esternito V com oito setas mais longas e mais largas na margem posterior que as outras do esternito. Sintergosternito VII+VIII com um par de macrosetas. Tergito IX com 10 setas, sendo quatro macrosetas, de cada lado. Gonópodos longos, fortemente curvados no terço apical; seta acessória ausente; setas presentes somente no terço apical (Fig. 18).

Hospedeiro-tipo. Noctilio albiventris (Noctilionidae). Outros hospedeiros: Noctilio leporinus (Noctilionidae); Mormoops megalophylla, Pteronotus parnellii (Mormoopidae); Anoura caudifer, Artibeus jamaicensis, A. lituratus, A. obscurus, Carollia brevicauda, C. castanea, C. perspicillata, C. subrufa, Choeronischus godmani (Thomas, 1903), Chiroderma villosum, Desmodus rotundus, Glossophaga soricina, Lonchophylla mordax Thomas, 1895, L. robusta, Lonchorhina aurita, Macrophyllum macrophyllum, Phyllostomus discolor, P. elongatus, P. hastatus, Sturnira lilium, S. tildae, Tonatia silvicola, Trachops cirrhosus (Phyllostomidae); Natalus stramineus (Natalidae) e Myotis nigricans (Vespertilionidae).

Distribuição geográfica. México, El Salvador, Panamá, Trinidad e Tobago, Venezuela, Colômbia, Guiana, Suriname, Guiana Francesa, Brasil (Pará, Rondônia, São Paulo, Paraná) e Peru. 
Material paranaense examinado. Parque Nacional do Iguaçu: 1 macho em Carollia perspicillata, Graciolli, Lima \& Rocha leg., 14/X/1998; 2 fêmeas em C. perspicillata, Graciolli, Lima \& Rochaleg., 14/I/1999; 1 macho em C. perspicillata, Graciolli \& Rocha leg., 12/III/1999; 1 macho em C. perspicillata, Graciolli \& Rocha leg., 14/III/1999; Parque Estadual Marumbi: 1 fêmea em Carollia perspicillata (Coleção de Vertebrados de Depto. Zoologia), 25 a 26/IX/1982.

Material adicional examinado: PANAMÁ: Canal Zone, mine shoft, Coco Plantation, Gamboa Road, 1 macho (Parátipo), Keenan \& Tipton leg. 09/IX/1959. (MZSP); Colón, Buena Vista, caves, 1 fềmea (Parátipo), Keenan \& Tipton leg. 03/IX/1959 (MZSP).

Comentário. Embora o hospedeiro-tipo seja Noctilio leporinus, existem registros de um grande número de hospedeiros. Strebla guajiro parasita principalmente Carollia perspicillata em toda sua distribuição geográfica.

\section{Strebla mirabilis (Waterhouse, 1879)}

\section{Fig. 37}

Euctenodes mirabilis Waterhouse, 1879: 310, localidade-tipo: Colômbia.

Euctenodes guarani Garcia \& Casal, 1965: 13, localidade-tipo: Paraguai.

Strebla mirabilis; Wenzel et al., 1966: 615; Wenzel, 1976: 155, Syn.: guarani; Guerrero, 1996a: 3 (diagnose).

Diagnose. Cabeça: frontoclípeo dividido em duas placas denteadas e pequenas anteriormente. Occipício com três a quatro setas espiniformes de cada lado. Olho composto com cerca de oito facetas. Tórax: mesonoto com áreas desprovidas de setas. Três filas de setas transversais entre a sutura pigmentada e a sutura transversal. Setas antescutelares mais largas e três vezes mais longas que as setas imediatamente anteriores a elas. Pernas: metatíbia com duas macrosetas subapicais. Abdômen: conetivo abdominal lateral com setas mais espaçadas e longas que as ventrais do conetivo. Lóbulo do tergo I+II com 15 setas. Esternito II subquadrado e estreito, com 14 setas na margem posterior, das quais duas setas maiores do que as outras, e 29 setas discais.

Fêmea. Abdômen: Tergito VII unido ao epiprocto, pentagonal, área anterior bastante estreitada, com dois pares de setas. Um par de macrosetas laterais e um par de setas menores mais internamente. Epiprocto com quatro macrosetas distais, sendo o par central visivelmente mais longo que o lateral, e um par de setas anteriores a estas. Esternito VII dividido em dois escleritos com 16 a 17 setas em cada um.

Macho. Abdômen: Esterno V com nove setas mais grossas que as outras do esclerito na margem posterior. Sintergosternito VII+VIII com um par dorsal de macrosetas e um par de setas mais curtas entre elas. Tergito IX com 17 a 20 setas. Gonópodos longos e finos, curvados, ápice arredondado; seta acessória com inserção posterior à macroseta (Fig. 19).

Hospedeiro-tipo. Não determinado. Outros hospedeiros: Pteronotus parnelli (Mormoopidae); Artibeus jamaicensis, A. lituratus, Carollia perspicillata, Chrotopterus auritus, Desmodus rotundus, Diphylla ecaudata, Glossophaga soricina, Mimon bennettii, Phyllostomus discolor, P. elongatus, P. hastatus, Tonatia bidens e Trachops cirrhosus (Phyllostomidae). 
Distribuição geográfica. México, Guatemala, Costa Rica, Panamá, Trinidad e Tobago, Venezuela, Colômbia, Brasil (Pará, Distrito Federal, Paraná), Peru, Bolívia e Paraguai.

Material paranaense examinado. Colombo: 1 macho em Mimon bennettii, Graciolli leg., 25/VI/1998; Parque Nacional do Iguaçu: 1 fềmea em Tonatia bidens, Sekiama leg., 22/XII/1998; 1 fềmea em T. bidens, Sekiama leg., 09/IV/1999.

Material adicional examinado. PANAMÁ: Chilbrilo Caves, 3 machos e 3 fềmeas (Parátipos) em Phyllostomus hastatus panamensis, Keenan \& Tipton leg., 28/X/1959 (MZSP).

Comentário. Espécie muito semelhante à Strebla kohlsi Wenzel, 1966 e $S$. paramirabilis Wenzel, 1976. WeNZEL (1976: 156) suspeitou que S. kohlsi seja sinônimo de $S$. mirabilis, já que são diferenciadas sutilmente pelo número de setas do esternito VII da fêmea; os machos são idênticos (GUERRERo 1996a: 10).

\section{Strebla wiedemanni Kolenati, 1856}

Fig. 20

Hippobosca vespertilionis Fabricius, 1805: 339; ICZN, 1936: 29 (supressão do nome).

Strebla wiedemanni Kolenati, 1856: 46, nom. n. para vespertilionis Fabricius, 1805, localidade-tipo: Chiapas, Yucatan, México; Wenzel, 1970: 15, Syn.: vespertilionis; Wenzel, 1976: 160, Syn.: tupi; Guerrero, 1996a: 2 (diagnose).

Euctenodes tupi Garcia \& Casal, 1965: 16, localidade-tipo: Monte Alegre, São Paulo, Brasil.

Strebla vespertilionis; Wenzel et al., 1966: 609 (redescrição), localidade-tipo: Neótipo, Pernanbuco, Brasil.

Diagnose. Cabeça: frontoclípeo dividido em duas placas denteadas e pequenas anteriormente. Olho composto com 10 facetas. Pós-vértice e lóbulos occipitais com setas finas, nenhuma espiniforme. Tórax: mesonoto coberto de setas, exceto margem anterior do prescuto. Prescuto com seis setas espiniformes próximas à margem anterior. Sutura longitudinal secundária pouco visível. Três filas de setas entre as suturas secundária e transversal. Setas antescutelares três vezes mais compridas que a fila de setas anterior. Pernas: metatíbia com duas filas de setas dorsais mais longas do que as outras setas. Abdômen: lóbulo do sintergito I+II com cerca de 15 setas. No terço basal, setas do conetivo abdominal lateral espaçadas e mais curtas que as outras do conetivo.

Fêmea. Abdômen: Tergito VII em forma de losango de base reta, com três pares de setas; um par de macrosetas e posteriormente dois pares de setas mais curtas, sendo o par anterior mais curto que o posterior. Epiprocto com 4 setas discais e um par de setas anterolaterais mais curtas. Esternito VII dividido em dois escleritos com mais ou menos 18 setas em cada um.

Macho. Abdômen: Esternito $\mathrm{V}$ com 12 setas na margem posterior, mais longas que as setas discais. Esternito VI presente. Sintergosternito VII+VIII dorsalmente com uma macroseta e ao lado desta uma seta diminuta. Cada lado do tergito IX com três macrosetas dorsais, quatro setas lateroposteriores, sendo duas macrosetas e 15 setas lateroventrais. Gonópodos longos e finos, levemente curvados no ápice, o qual é arredondado; inserção da seta acessória posterior à macroseta (Fig. 20). 
Hospedeiro-tipo. "America meridionalis vespertilione" (FABRICUS 1805). Outros hospedeiros: Peropteyx macrotis (Wagner, 1843) (Emballonuridae); Mormoops megaphylla, Pteronotus parnellii (Mormoopidae); Anoura caudifer, A. geoffroyi, Artibeus jamaicensis, A. lituratus, A. obscurus, Carollia perspicillata, Chiroderma villosum, Chrotopterus auritus, Desmodus rotundus, Diphylla ecaudata, Glossophaga longirostris, G. soricina, Macrophyllum macrophyllum, Phylloderma stenops, Phyllostomus discolor, P. hastatus, Platyrrhinus dorsalis, Sphaeronycteris toxophyllum, Sturnira lilium, S. tildae, Uroderma magnirostrum Davis, 1968 (Phyllostomidae); Natalus stramineus (Natalidae); Myotis nigricans (Vespertilionidae); Eumops auripendulus (Shaw, 1800), E. perotis (Schinz, 1821) e Molossus bondae J.A. Allen, 1904 (Molossidae).

Distribuição geográfica. México, Jamaica, Guatemala, Honduras, El Salvador, Panamá, Trinidad e Tobago, Venezuela, Colômbia, Suriname, Brasil (Pará, Pernambuco, Bahia, Mato Grosso, Minas Gerais, Distrito Federal, Rio de Janeiro, São Paulo, Paraná), Equador, Peru, Bolívia e Argentina.

Material paranaense examinado. Almirante Tamandaré: 1 macho e 1 fêmea em Desmodus rotundus, Viana leg., 30/IV/1985 (DZUP); Campo Largo: 5 machos e 1 fêmea em D. rotundus, 20/I/1998; Rio Branco do Sul: 5 machos em D. rotundus, Dos Santos leg., 21/VI/1988; São Jerônimo da Serra: 3 machos e 4 fêmeas em $D$. rotundus, Dos Santos leg., 20/VII/1987.

Comentário. Parasito primário de Desmodus rotundus e ocorre em toda distribuição geográfica do hospedeiro. SANTOS (1991) registrou primeiramente Strebla wiedemanni no estado do Paraná sobre D. rotundus.

\section{Paraeuctenodes Pessoa \& Guimarães, 1936}

Paraeuctenodes Pessoa \& Guimarães, 1936: 257; Wenzel, 1976: 162 (chave de identificação das espécies); Guerrero, 1996a: 18 (diagnose).

Espécie-tipo: Paraeuctenodes longipes Pessoa \& Guimarães, 1936, por designação original.

Diagnose. Cabeça: palpos fusionados à cabeça. Frontoclípeo e pós-vértice grandes e bem desenvolvidos. Gena e pós-gena bem desenvolvidas. Ctenídio completo, ocupando todo o lado ventral da cabeça e estendendo-se até o lado laterodorsal. Tórax: mesonoto totalmente coberto de setas e com uma sutura pigmentada prescutal. Asas desenvolvidas. Pernas anteriores curtas e grossas, as médias um pouco mais longas e as posteriores muito longas, com os fêmures mais longos que o tórax e as tíbias mais longas, comprimidas lateralmente e sem macrosetas. Abdômen: conetivo dorsal sem setas.

Comentário. Abriga duas espécies válidas (Guerrero 1996a), Paraeuctenodes longipes Pessôa \& Guimarães, 1936 e P. similis Wenzel, 1976, que parasitam Glossophaginae e Carolliinae. Ambas espécies já foram registradas no Brasil (WENZEL 1976; GUERRERO 1997). 


\section{Paraeuctenodes longipes Pessoa \& Guimarães, 1936}

Fig. 21

Paraeuctenodes longipes Pessôa \& Guimarães, 1936: 258, localidade-tipo: Ipiranga, São Paulo, São Paulo, Brasil; Wenzel, 1976: 102 (diagnose); Guerrero, 1996a: 18 (diagnose).

Diagnose. Cabeça: pouco mais longa que larga em vista ventral. Occipício com três setas espiniformes. Olho composto com sete facetas. Tórax: mais longo que largo. Abdômen: lóbulo do sintergito I+II com 11 a 13 setas.

Fêmea. Abdômen: Tergito VII pequeno e elíptico, com um par de setas. Epiprocto com quatro macrosetas distais e um par de setas discais. Esternito VII dividido em dois escleritos pequenos e ovais, com seis setas em cada um.

Macho. Abdômen: Esternito V com seis setas mais longas na margem posterior que as discais. Sintergosternito VII+VIII com um par de setas. Tergito IX com três macrosetas laterais e quatro a cinco setas ventrais de cada lado. Gonópodos curtos e altos, curvados, bruscamente estreitado no ápice; inserção da seta acessória posterior à macroseta (Fig. 21).

Hospedeiro-tipo. Anoura caudifer (Phyllostomidae). Outros hospedeiros: Anoura geoffroyi, Artibeus lituratus, Carollia perspicillata, Glossophaga longirostris, G. soricina, Phyllostomus hastatus (Phyllostomidae); Histiotus velatus (I. Geoffroy, 1824)(Vespertilionidae); e Nictinomops lauticaudatus E. Geoffroy, 1824 (Molossidae).

Distribuição geográfica. México, Guatemala, Nicarágua, Venezuela e Brasil (São Paulo, Rio Grande do Sul).

Material paranaense examinado. Nenhum.

Material adicional examinado. BRASIL, São Paulo: São Paulo, Ipiranga, 1 macho (Parátipo) em Histiotus velatus, J. Lima leg., 04/XII/1936 (MZSP); Rio Grande do Sul, Dom Pedro de Alcântara, 4 machos e 1 fêmea em Glossophaga soricina, Graciolli \& Rui leg., 19/VI/1997 (DZUP).

Comentário. Espécie não encontrada no Paraná. No entanto, pela distribuição no Rio Grande do Sul e em São Paulo, deve ocorre neste Estado.

\section{Paraeuctenodes similis Wenzel, 1976}

Fig. 22

Paraeuctenodes similis Wenzel, 1976: 164, localidade-tipo: $13 \mathrm{~km}$ ao NE de Icabaru, Bolivar, Venezuela; Guerrero, 1996a: 18 (diagnose).

Diagnose. Cabeça: duas vezes mais larga que longa em vista ventral. Occipício com sete setas na margem posterior e duas pequenas setas discais. Olho composto com sete facetas. Tórax: tão longo quanto largo, mesonoto coberto de setas. Setas de tamanho uniforme, exceção das setas da fila anterior às suturas pigmentada e transversal, setas antescutelares longas. Três filas transversais de setas entre a sutura pigmentada e a sutura transversal. Fila antescutelar com cerca de 14 setas mais largas que as setas imediatamente anteriores. Abdômen: lóbulo do Sintergito I+II com 15 setas. 
Fêmea. Abdômen: Tergito VII com dois pares de setas. Epiprocto com quatro macrosetas distais.

Macho. Abdômen: Esternito V coberto de setas. Com seis a sete setas mais longas do que o esternito na margem posterior. Sintergosternito VII+VIII com setas oblíquas pequenas. Tergito IX com oito setas distribuídas em duas filas transversais. Três macrosetas posteriores e cinco setas menores anteriores. Gonópodos finos e longos, curvados no ápice, o qual é arredondado; macroseta muito longa, ultrapassando o ápice; inserção da seta acessória posterior à macroseta; com duas setas dorsais (Fig. 22).

Hospedeiro-tipo. Carollia perspicillata (Phyllostomidae). Outros hospedeiros: Carollia brevicauda e Trachops cirrhosus (Phyllostomidae). ná).

Distribuição geográfica. Venezuela, Colômbia e Brasil (São Paulo, Para-

Material paranaense examinado. Parque Estadual Marumbi: 1 macho em Carollia perspicillata (Coleção de Vertebrados de Depto. Zoologia), 25 a 26/IX/1982.

Comentário. Espécie encontrada principalmente sobre Carollia perspicillata. GuimarãEs (1944) registrou em Monte Alegre, São Paulo, P. longipes sobre $C$. perspicillata. Como $P$. similis só foi descrita em 1976 por WENZEL, que possui material proveniente de São Paulo, acreditamos que este registro refira-se na realidade à $P$. similis. No entanto, este material não foi encontrado no MZSP, onde deveria estar depositado.

\section{Anastrebla Wenzel, 1966}

Strebla; Kessel, 1924: 409 (diagnose); Kessel, 1925: 29 (diagnose, chave de identificação das espécies). Erro de identificação.

Anastrebla Wenzel, 1966 in Wenzel et al.: 627; Wenzel, 1976: 165 (chave de identificação das espécies); Guerrero, 1996a: 19 (diagnose), 22 (chave de identificação das espécies)

Espécie-tipo de Anastrebla: Anastrebla modestini Wenzel, 1966, por designação original.

Diagnose. Cabeça: palpos fusionados à cabeça. Frontoclípeo e pós-vértice grandes e bem desenvolvidos. Gena bem esclerotinizada. Posgena reduzida a uma pequena placa, entre o ctenídio e os laterovértices e com uma grande seta remiforme dirigida lateralmente. Ctenídio completo, ocupando todo o lado ventral da cabeça, estendendo-se até o lado laterodorsal. Tórax: coberto de setas; mesosterno com áreas sem setas e uma sutura pigmentada prescutal. Lóbulo metasternal reduzido e arredondado. Asas: grandes, desenvolvidas, normais em venação e com setação reduzida em algumas veias. Pernas anteriores muito longas, com os fêmures mais longos que o tórax e as tíbias muito longas e finas e sem macrosetas. Abdômen: conetivo dorsal com duas filas irregulares de setas diminutas.

Comentário. Gênero formado por cinco espécies (GUERRERo 1996a) que. parasitam Glossophaginae. No Brasil, foram registradas Anastrebla caudiferae Wenzel, 1976 (Kessel 1924; Graciolli \& Rui 2001) e A. modestini Wenzel, 1966 (WhitAKER \& MUMFord 1977; GRACIOLLI \& RUi 2001). 


\section{Anastrebla caudiferae Wenzel, 1976}

Fig. 41

Strebla vespertilionis; Speiser, 1900a: 38; Kessel, 1924: 413 (redescrição); Kessel, 1925: 29 (diagnose). Erro de identificação.

Anastrebla caudiferae Wenzel, 1976: 166, Localidade-tipo: Curupao, Guarenas, Miranda, Venezuela; Guerrero, 1996a: 21 (diagnose).

Diagnose. Cabeça: mais longa que larga. Olho composto com sete a oito facetas distintas. Asas normais, Rl e 1A glabras. Abdômen: conetivo abdominal dorsal com duas filas longitudinais de setas obsoletas.

Fêmea. Abdômen: Tergito VII pequeno e elíptico transversalmente, com um par de macrosetas laterais e um par de setas discais entre as primeiras. Epiprocto com quatro macrosetas distais e um par de setas laterais. Esternito VII dividido em dois escleritos com 10 setas em cada um.

Macho. Abdômen: Sintergito VII+VIII com quatro setas de cada lado. Tergito IX com oito setas de cada lado. Gonópodos curtos e curvados; inserção da seta acessória posterior à macroseta (Fig. 23).

Hospedeiro-tipo. Anoura caudifer (Phyllostomidae). Outro hospedeiro: Anoura sp.

Distribuição geográfica. Venezuela e Brasil (Paraná, Santa Catarina, Rio Grande do Sul).

Material paranaense examinado. Tunas do Paraná: Grutas de Campinhos, 2 machos e 1 fêmea em Anoura caudifer, R. Lange leg., VII/1947 (MHNCI).

Comentário. Espécie registrada primeiramente por KESSEL (1924: 414; 1925: 29), que analisou exemplares provenientes de Joinville, Santa Catarina, coletados sobre Lonchoglossa caudifera (=Anoura caudifer). A autora identificou o material como Strebla vespertilionis (Fabricius, 1805) (=Strebla wiedemanni).

\section{Anastrebla modestini Wenzel, 1966}

Fig. 24

Anastrebla modestini Wenzel, 1966 in Wenzel et al., 1966: 629, localidade-tipo: Casa Lewis, Cerro Punta, Chiriquí, Panamá; Guerrero, 1996a: 20 (diagnose).

Diagnose. Cabeça: comprimento e largura semelhantes. Olho composto com sete a oito facetas distintas. Asas: R1 com setas dorsais apenas na parte distal; 1 A pilosa, com exceção da base. Abdômen: conetivo abdominal dorsal com duas fileiras irregulares de setas obsoletas.

Fêmea. Abdômen: Tergito VII mais longo que amplo, com duas macrosetas laterais e duas setas discais posteriores. Epiprocto com quatro macrosetas discais e um par de setas laterais. Esternito VII dividido em dois escleritos com 12 setas em cada um.

Macho. Abdômen: esternito V pouco esclerotinizado ou ausente. Sintergosternito VII+VIII com quatro ou cinco macrosetas laterais, sendo a mais ventral de menor tamanho. Tergito IX com 18 setas de cada lado. Gonópodos curvados; inserção da seta acessória posterior à macroseta (Fig. 24). 
Hospedeiro-tipo. Anoura geoffroyi (Phyllostomidae). Outros hospedeiros: Anoura caudifer, Carollia perspicillata e Lionycteris spurrelli Thomas, 1913 (Phyllostomidae).

Distribuição geográfica. México, Guatemala, El Salvador, Panamá, Trinidad e Tobago, Venezuela, Colômbia, Brasil (Minas Gerais, Paraná, Rio Grande do Sul) e Equador.

Material paranaense examinado. Curitiba: 2 machos em Anoura geoffroyi, 23/X/1998.

Material adicional examinado. BRAsIL, Rio Grande do Sul: Dom Pedro de Alcântara, 2 fêmeas em Anoura geoffroyi, Graciolli \& Rui leg., 06/IX/1997 (DZUP).

Comentário. Parasito primário de Anoura geoffroyi. Outros registros devem ser acidentais.

\section{Metelasmus Coquillett, 1907}

Metelasmus Coquillett, 1907: 292; Jobling, 1939: 494, Syn.: Leimosia; Guerrero, 1966a: 23 (diagnose). Leimosia Pessôa \& Galvão, 1936: 243.

Espécie-tipo de Metelasmus: Metelasmus pseudopterus Coquillett, 1907, designação original. Espécie-tipo de Leimosia: Leimosia setosa Pessôa \& Galvão, 1936, por designação original.

Diagnose. Cabeça: palpos fusionados à cabeça. Frontoclípeo e pós-vértice grandes e bem desenvolvidos. Gena e posgena bem desenvolvidas e esclerotinizadas, a pós-gena com uma grande seta remiforme dirigida lateralmente. Ctenídio completo, ocupando todo a face ventral da cabeça e estendendo-se até à porção látero-dorsal. Tórax: coberto de setas com alguns claros sem setas no mesesternito. Asas: braquípteras, reduzidas em venação e em setação. Pernas: anteriores curtas e grossas, medianas um pouco mais longas, posteriores longas com os fêmures mais curtos que o tórax; tíbias sem macrosetas. Abdômen: conetivo dorsal totalmente coberto de setas.

Comentário. Até o momento, é um gênero monotípico. No entanto, WENZEL (1976) examinou dois indivíduos sobre Sturnira ludovici na Venezuela, e acreditou ser uma espécie não descrita. Como os exemplares estavam bastante danificados, preferiu não descrevê-los.

\section{Metelasmus pseudopterus Coquillett, 1907}

Fig. 25

Metelasmus pseudopterus Coquillett, 1907: 292, localidade-tipo: Sapucay, Paraguai; Jobling, 1936: 371 (redescrição); Jobling, 1939: 494, Syn.: setosa; Guerrero, 1996a: 23 (diagnose); Autino et al., 1999: 140 (redescrição).

Leimosia setosa Pessôa \& Galvão, 1936: 244, localidade-tipo: Mogi das Cruzes, São Paulo, Brasil.

Diagnose. Fêmea. Abdômen: Tergito VII pequeno com duas macrosetas. Epiprocto na forma de semicírculo com quatro macrosetas distais e um par de setas menores. Esternito VII dividido em dois escleritos pequenos e elípticos com 5 a 6 setas em cada um.

Macho. Abdômen: Esterno VI presente. Sintergosternito VII+VIII com uma macroseta e uma seta dorsais e cinco a seis setas em volta do sétimo espiráculo em cada lado. Tergito IX com mais ou menos 12 setas de cada lado mais finas que as 
do conetivo abdominal. Gonópodos curtos e sinuosos; curvados a partir do terço posterior; inserção da seta acessória anterior à macroseta e cinco setas espiniformes ventrais, ápice dilatado e semicircular com setas marginais (Fig. 25).

Hospedeiro-tipo. Artibeus lituratus (Phyllostomidae). Outros hospedeiros: Peropterix macrotis (Emballonuridae); Artibeus amplus Handley, 1987, A. fimbriatus, A. jamaicensis, A. hartii, A. planirostris, Carollia perspicillata, Chiroderma villosum, Phyllostomus discolor, P. hastatus, Platyrrhinus helleri, Sturnira lilium, Uroderma magnirostrum, Vampyressa nymphaea (Phyllostomidae); e Myotis nigricans (Vespertilionidae).

Distribuição geográfica. México, Guatemala, Nicarágua, Costa Rica, Panamá, Venezuela, Colômbia, Suriname, Brasil (Pará, São Paulo, Santa Catarina, Rio Grande do Sul), Peru, Bolívia, Argentina e Paraguai.

Material paranaense examinado. Nenhum.

Material adicional examinado. Brasil, Rio Grande do Sul: Dom Pedro de Alcântara, 1 macho e 1 fêmeas em Artibeus fimbriatus, Graciolli \& Rui leg., 25/IV/1997 (DZUP); 1 macho e 1 fềmea em A. fimbriatus, Graciolli \& Rui leg., II/1997 (DZUP).

Comentário. Espécie não encontrada no Paraná. No entanto, pela distribuição no Rio Grande do Sul e em São Paulo, deve ocorrer neste Estado.

AGRADECIMENTOS. A Isaac Lima, M.Sc. Margareth Sekiama, M.Sc. Vlamir Rocha, M.Sc. Marcelo O. Bordignon e Dr. Nílton Cárceres pelo auxílio nas coletas do material. Aos curadores Dra. Eliane Cancello e Dr. Carlos Roberto Brandão do Museu de Zoologia da Universidade de São Paulo e Bióloga Márcia Arzuá do Museu de História Natural Capão da Imbuia, Curitiba pelo empréstimo de material. Ao Conselho Nacional de Desenvolvimento Científico e Tecnológico $(\mathrm{CNPq})$ pela bolsa de mestrado. 
Chave pictórica para gêneros e espécies de Streblidae

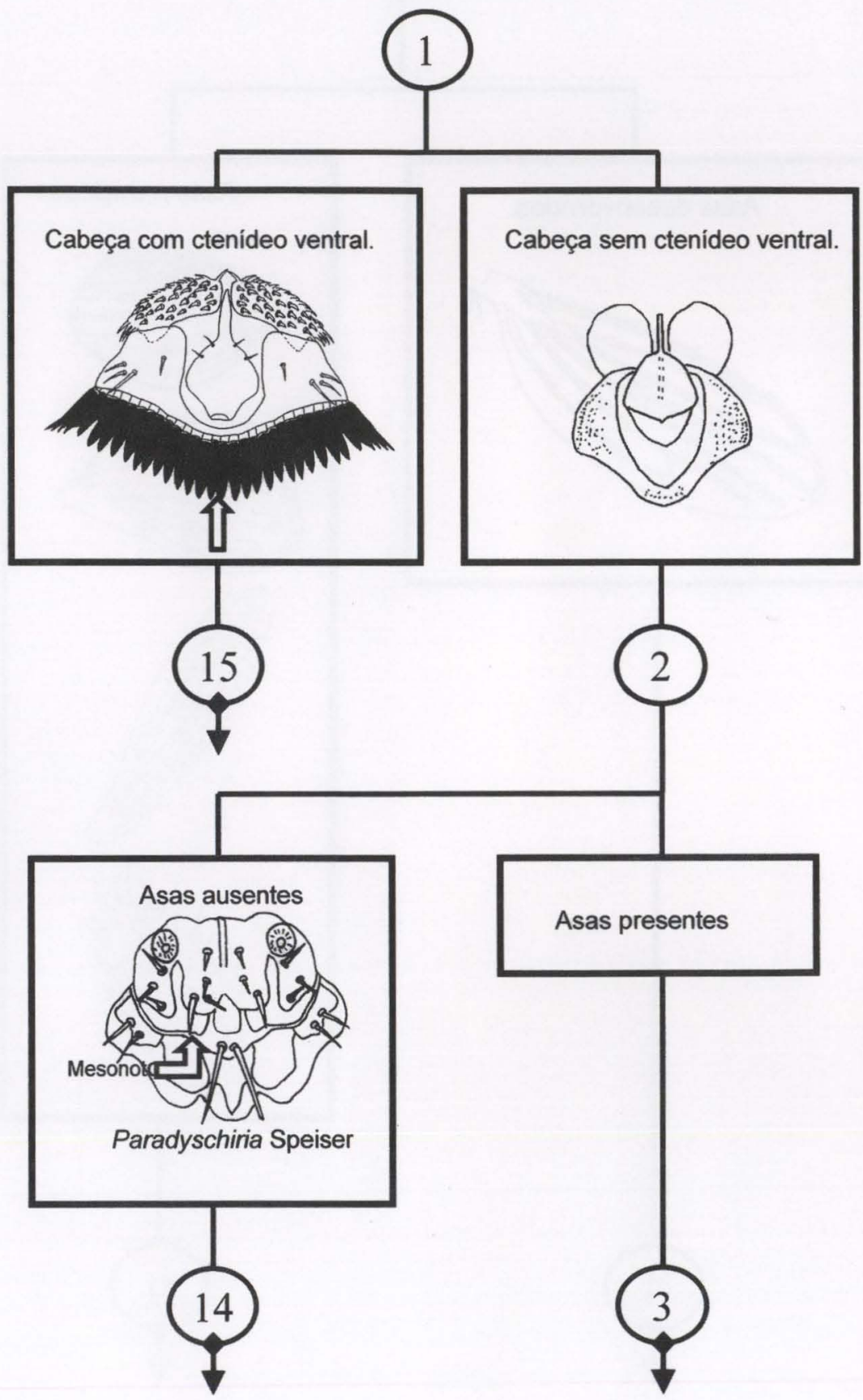




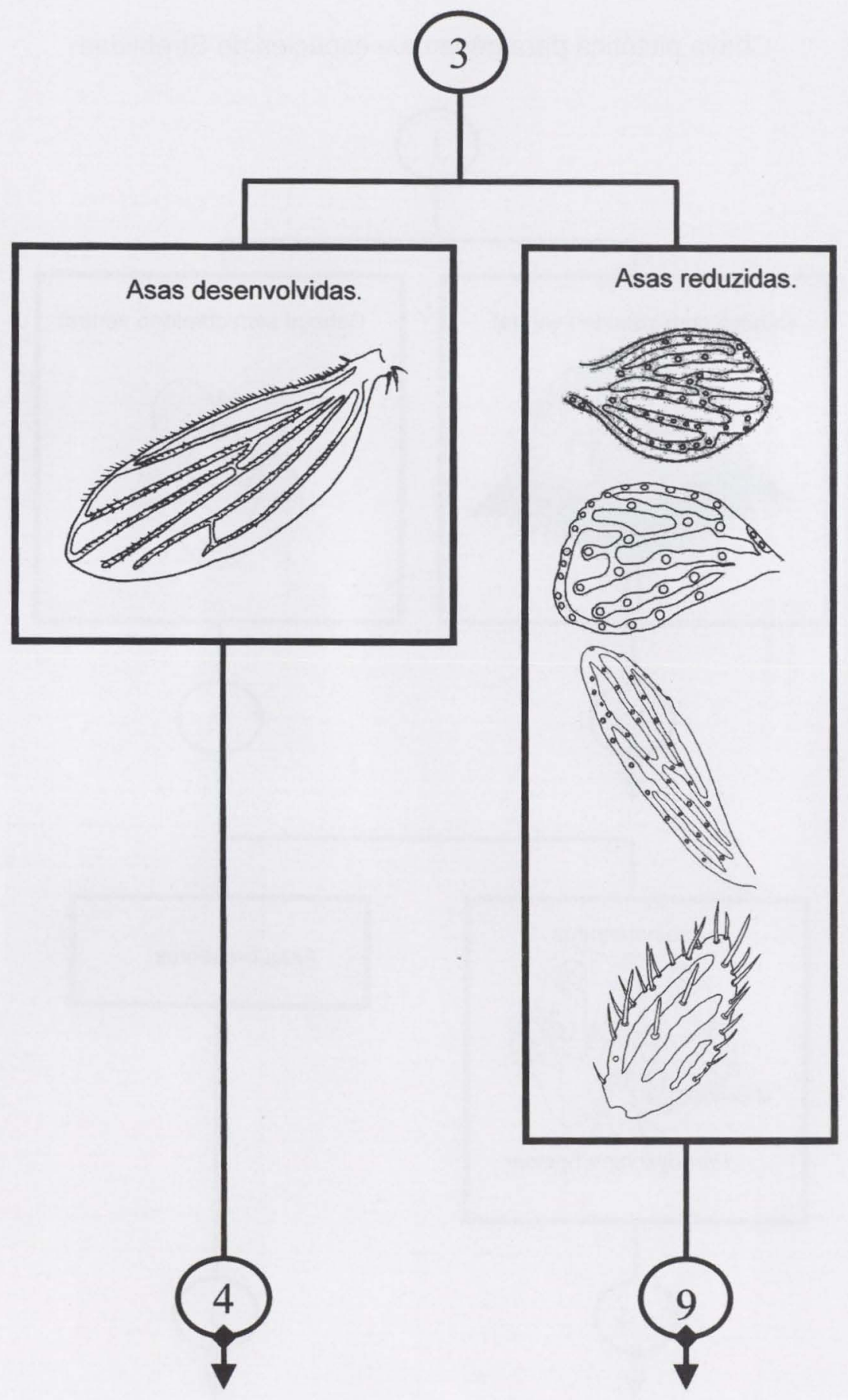

Revta bras. Zool. 18 (3): 907 - 960, 2001 


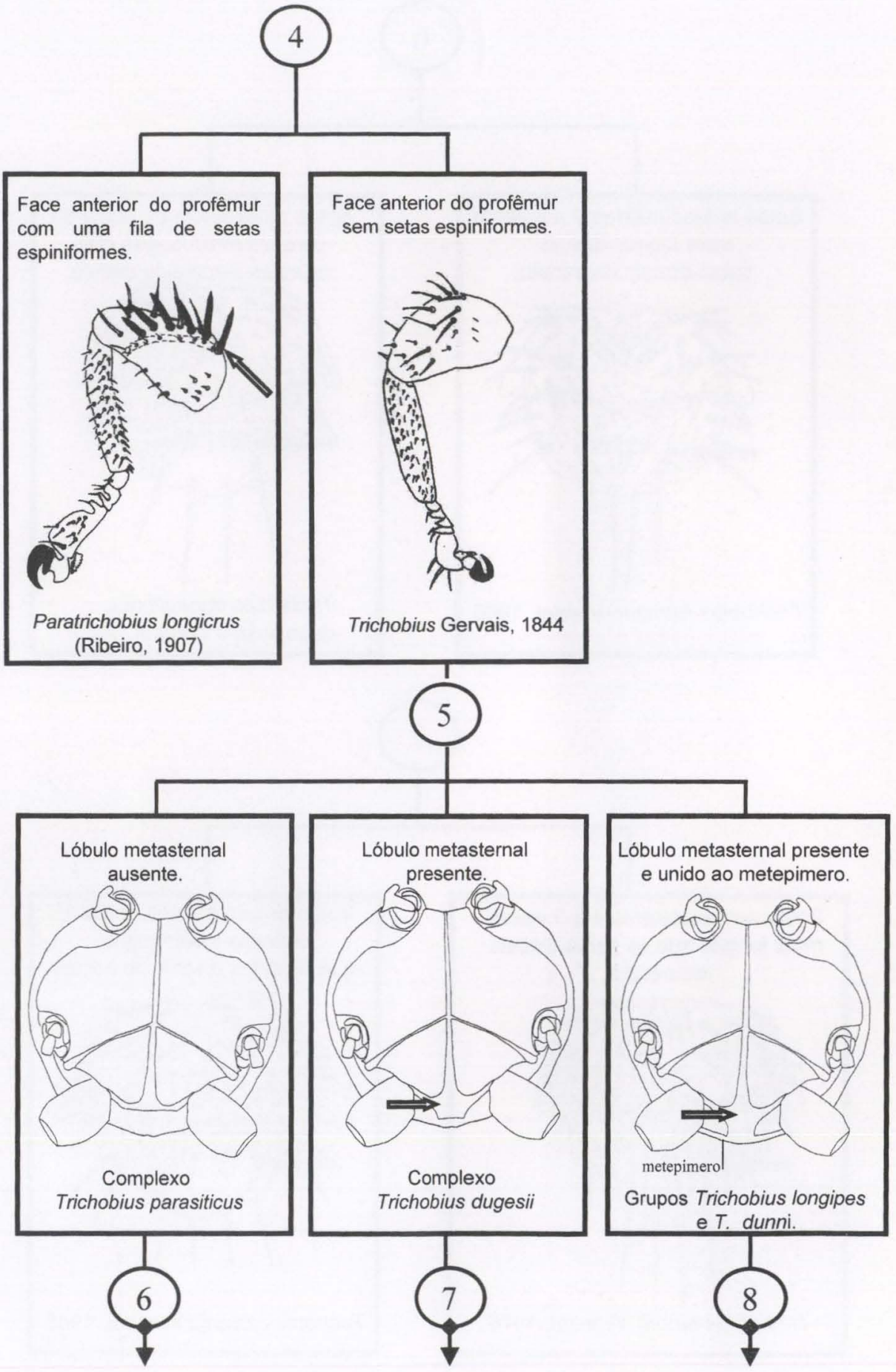



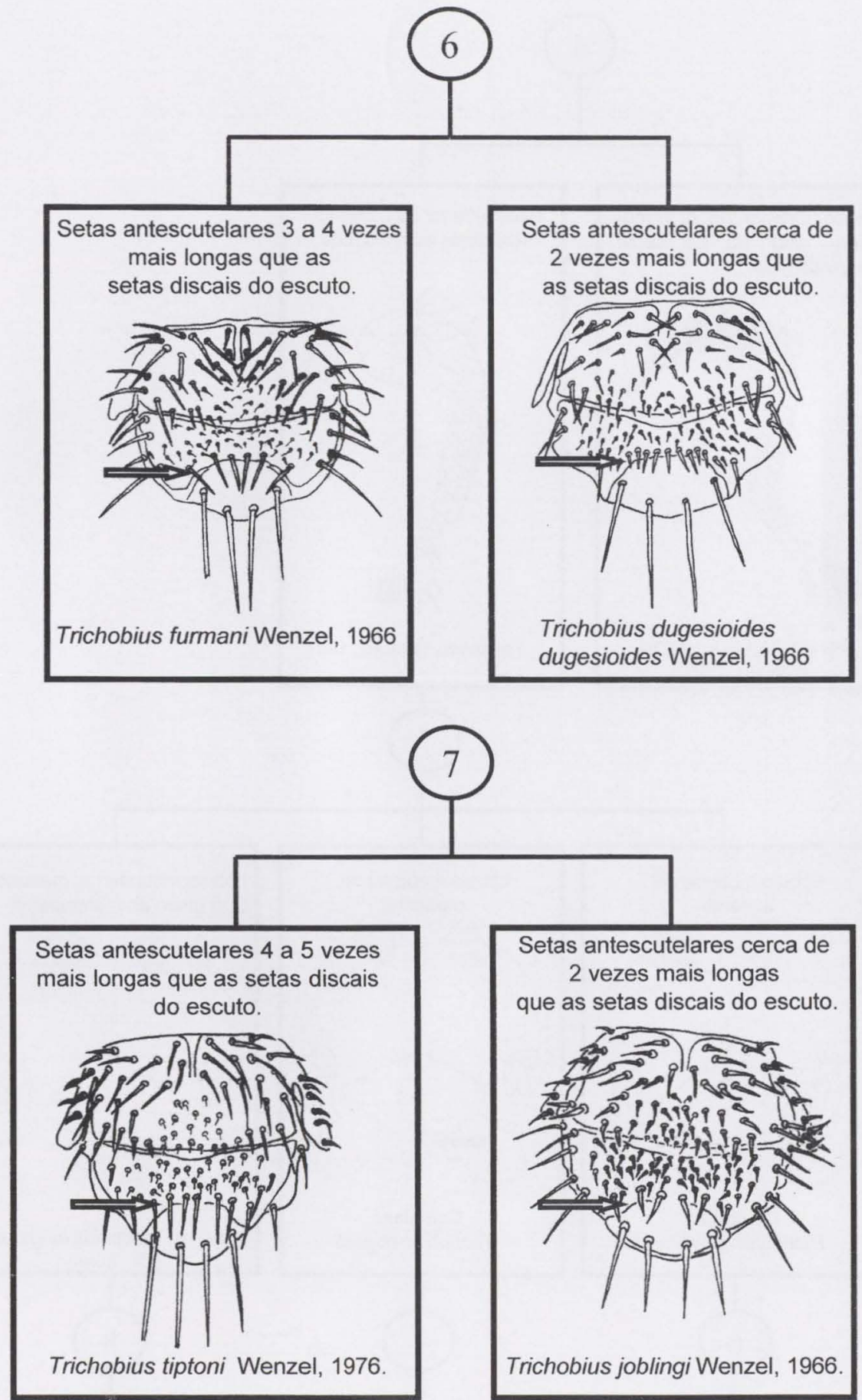


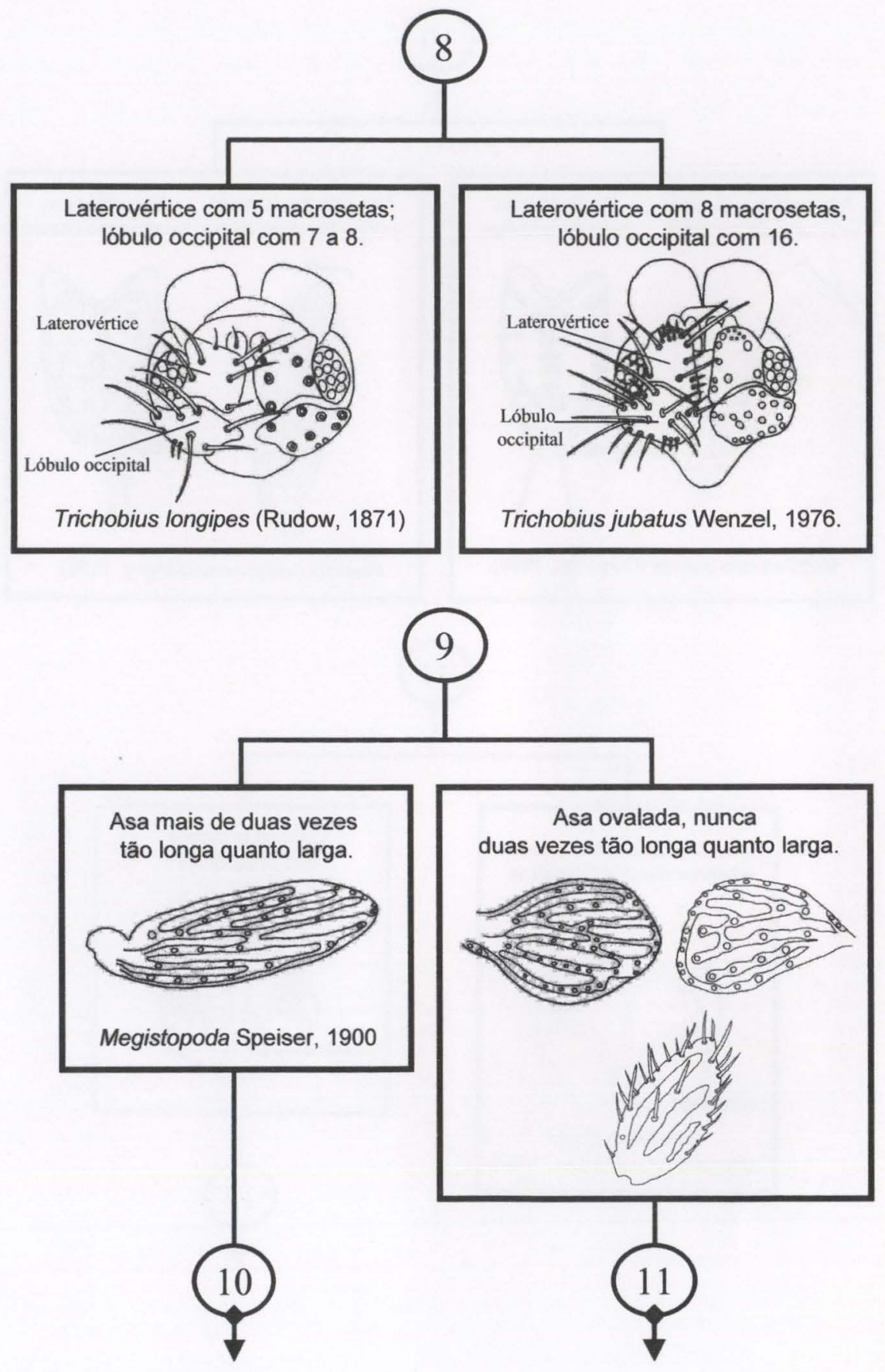




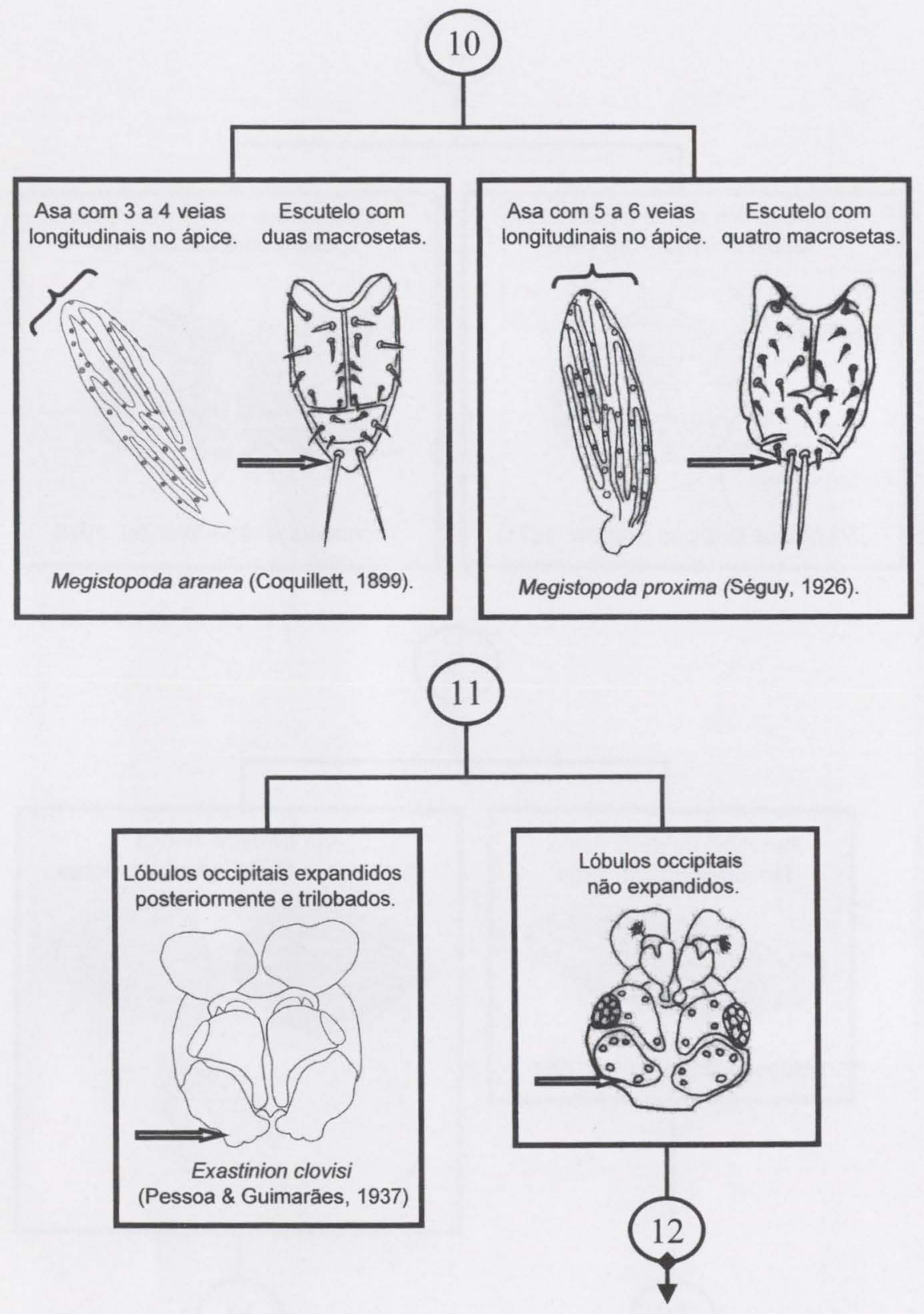




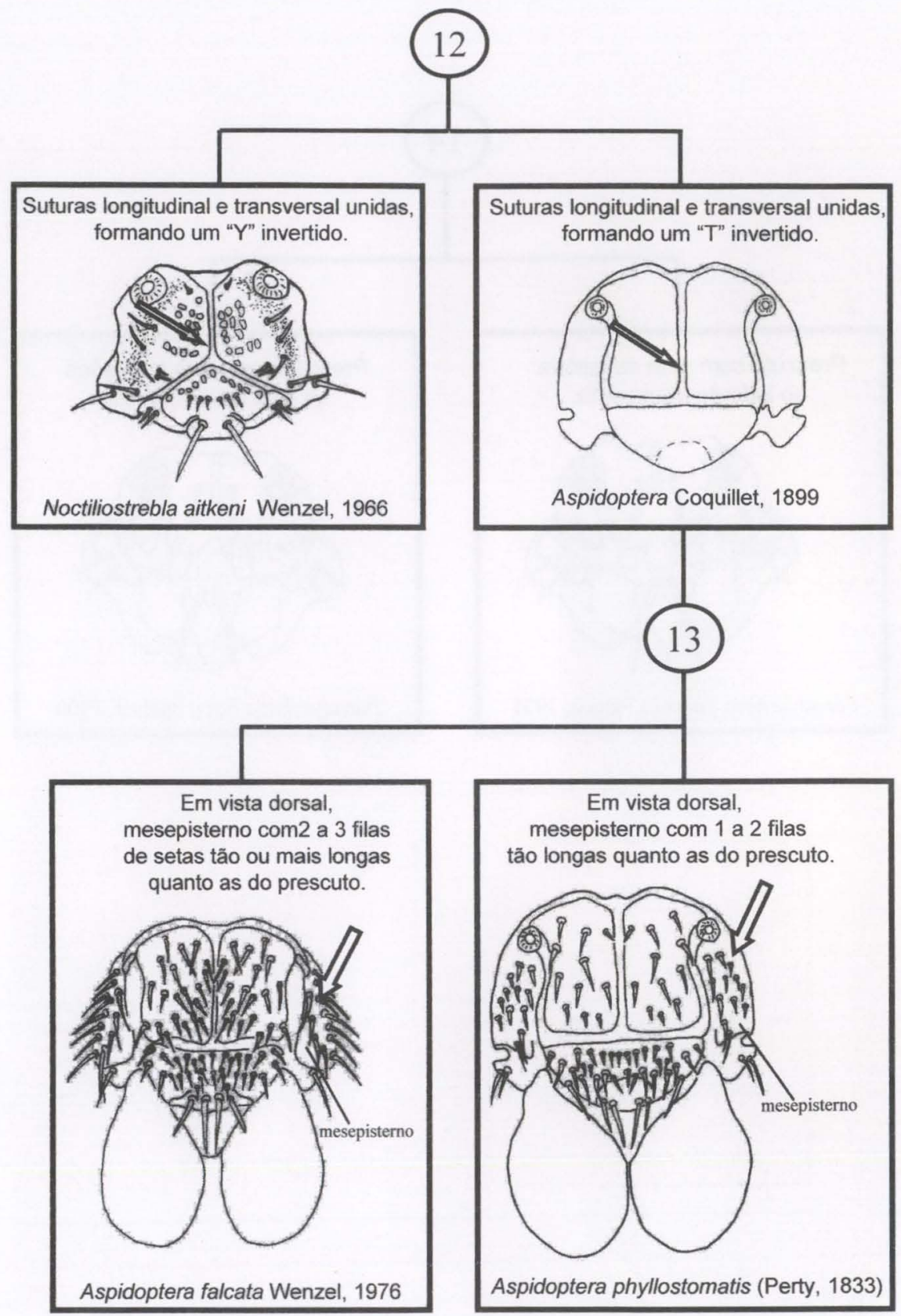




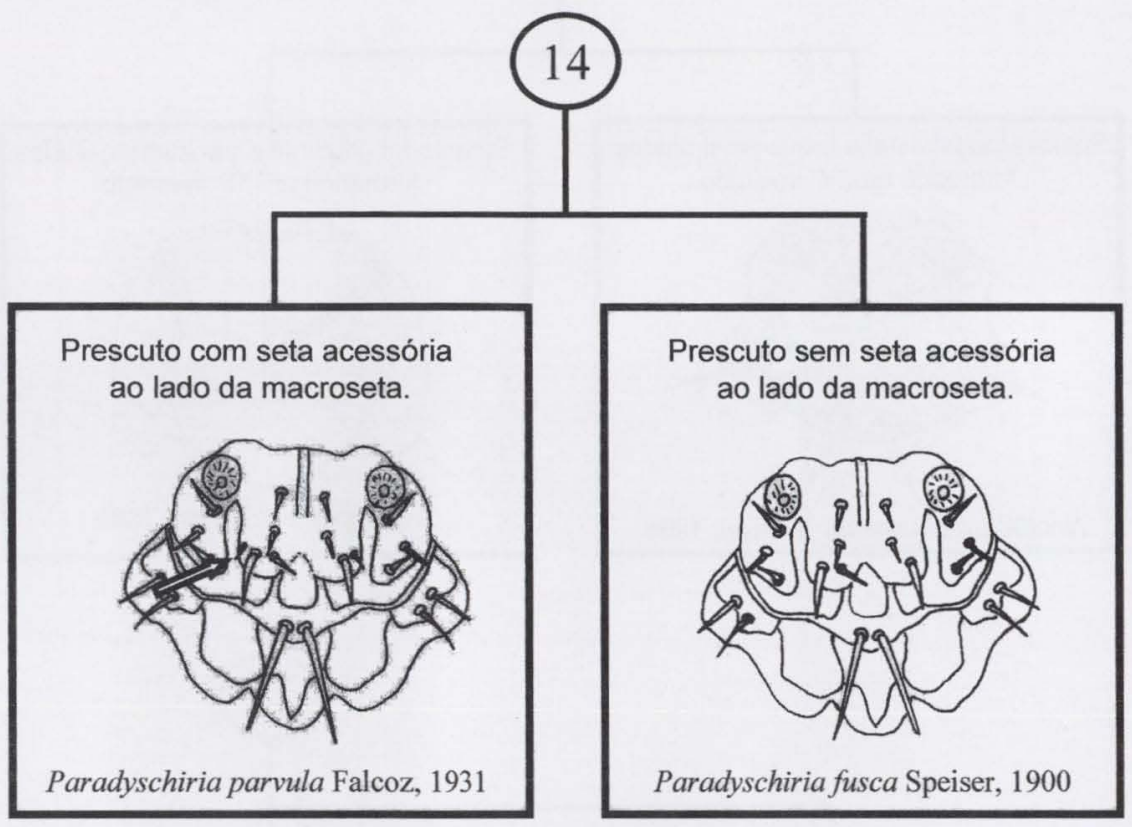




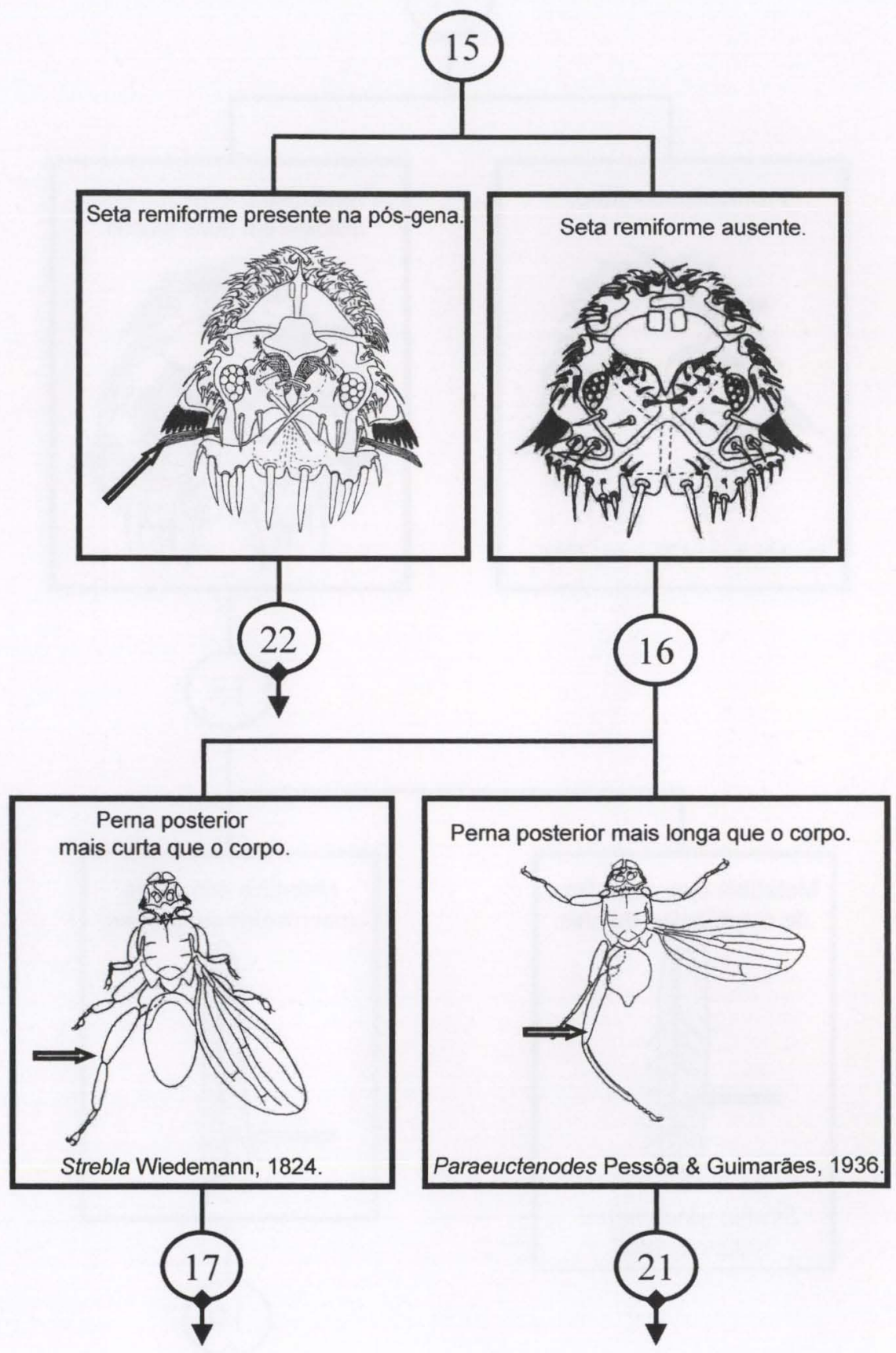




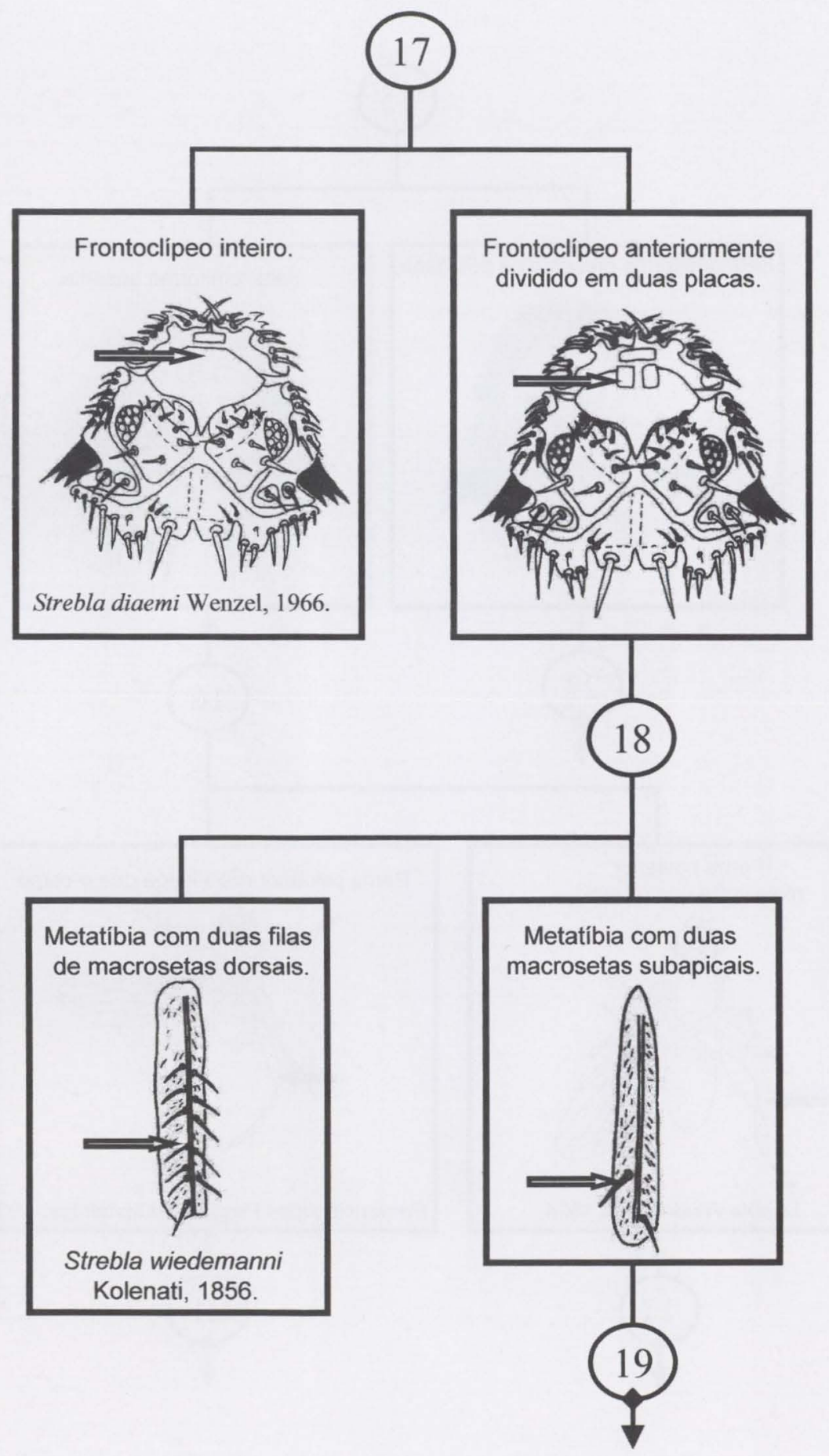




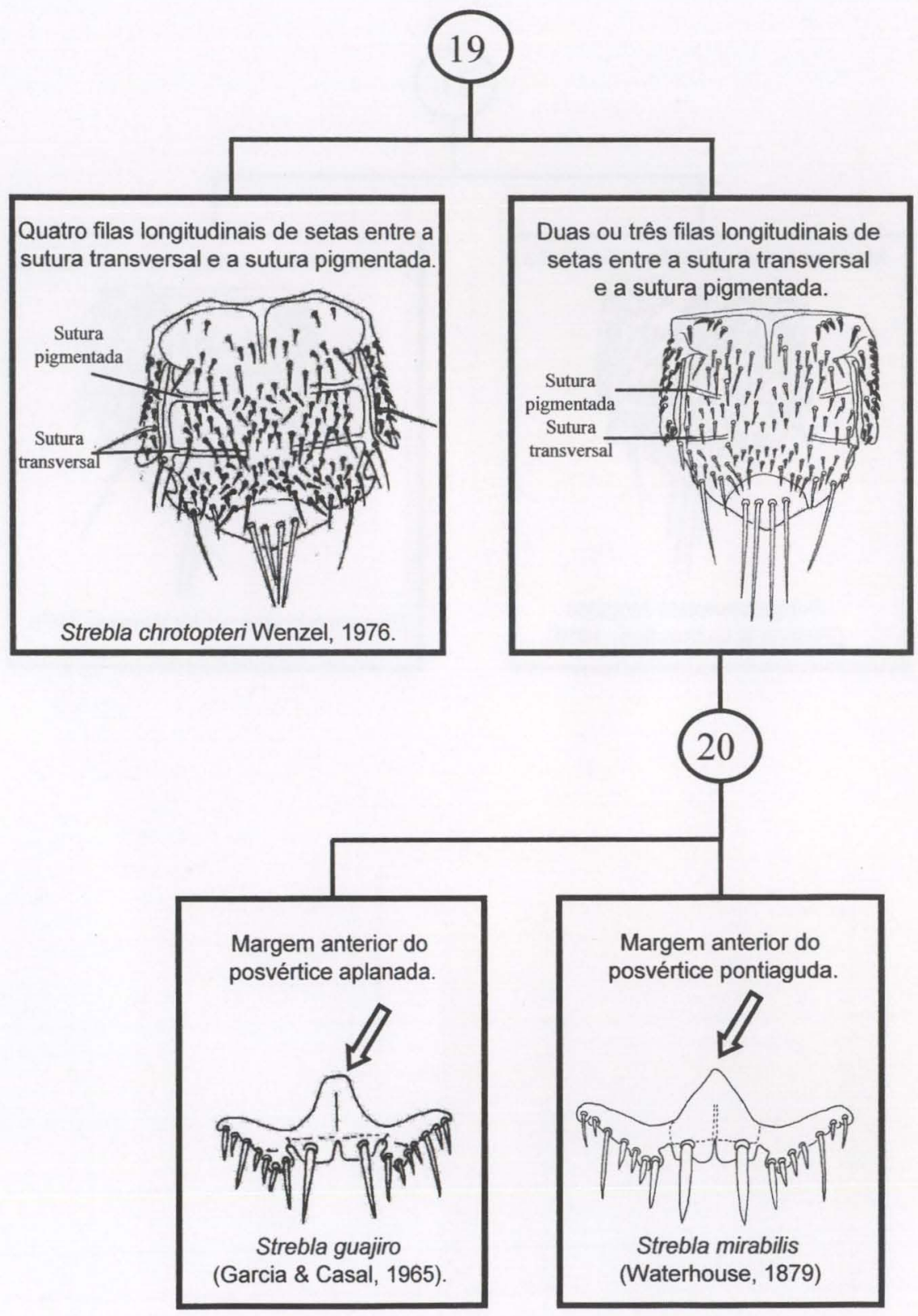




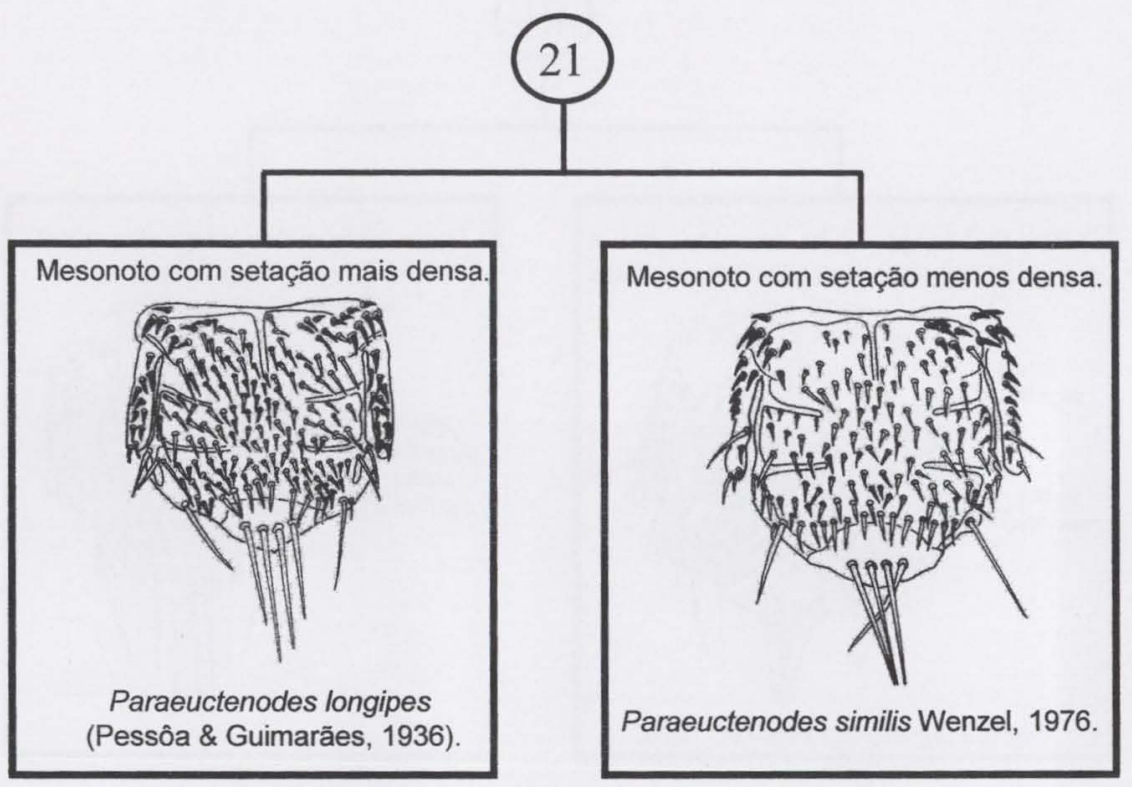




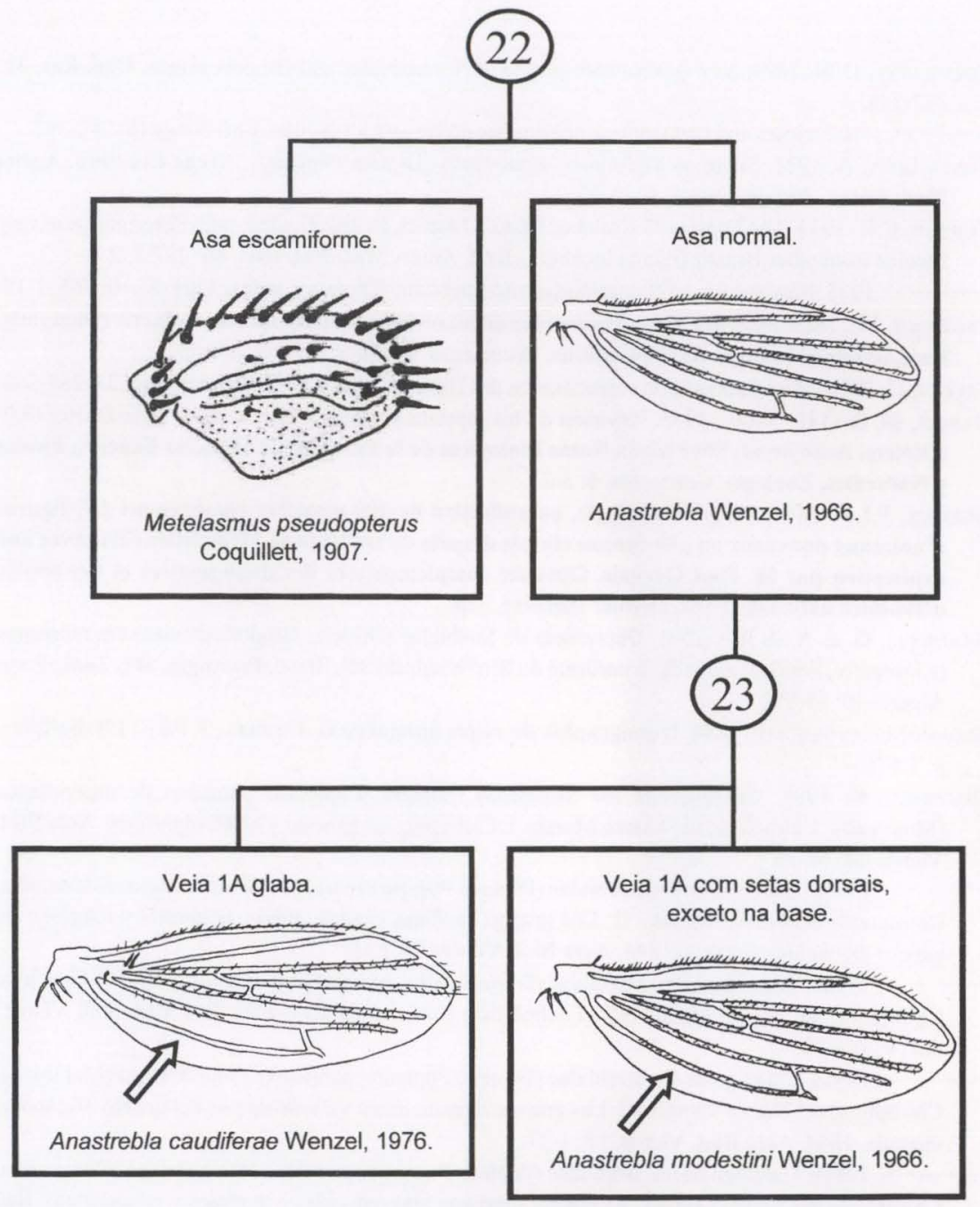

\section{REFERÊNCIAS BIBLIOGRÁFICAS}

AUtINO, A.G.; R.M. BARQueZ \& G.L. Claps. 1992. Nuevas citas de dipteros ectoparasitos (Streblidae) para murcielagos de la Argentina. Rev. Soc. Ent. Arg. 50: 248, 260.

Autino, A.G.; G.L. Claps \& M.P. BERTolini. 1998. Primeiros registros de insectos ectoparásitos (Diptera, Streblidae) de murciélagos de Parque Nacional Iguazú, Misiones, Argentina. Revta bras. Ent. 42: 59-63.

Autino, A.G.; G.L. Claps \& R.M. BARQuez. 1999. Insectos ectoparasitos de murcielagos de las Yungas de la Argentina. Acta Zool. Mex., n.s., 78: 119-169.

BarqueZ, R.M.; G.L. Claps \& A.G. Autino. 1991. Nuevos registros de ectoparasitos de murcielagos en el nororeste argentino. Rev. Soc. Ent. Arg. 49: 78-102.

Colmbra JR., C.E.A.; L.R. Guimarães \& D.A. Mello. 1984. Ocorrència de Streblidae (Diptera: Pupipara) em morcegos capturados em regiões de cerrado do Brasil Central. Revta bras. Ent. 28: 547-550. 
Coquillett, D.W. 1899. New genera and species of Nycteribiidae and Hippoboscidae. Can. Ent. 31: 333-336.

1907. Notes and descriptions of Hippoboscidae and Streblidae. Ent. News 18: 290-292.

Costa Lima, A. 1921. Sobre os Streblideos americanos (Diptera-Pupipara). Archs Esc. Sup. Agric. Med. Veter., Rio de Janeiro, 5: 17-33.

CurRAN, C.H. 1934. The Diptera of Kartabo, Bartica District, British Guiana, with descriptions of new species from other British Guiana localities. Bull. Amer. Mus. Nat. Hist. 66: 287-532.

- 1935. New species of Nycteribiidae and Streblidae (Diptera). Amer. Mus. Novit. 765: 1-15.

FABRICIUS, J.C. 1805. Systema Antliatorum secundum ordines, genera, species, adjectis synonym is, locis, observationibus, descriptionibus. Brunsvigae, Reichard, XIV $+373+30 p$.

FaLcoz, L. 1931. Matériaux pour la connaissance des Diptères Pupipares. I. Parasitology 23: 264-269.

GarCiA, M. \& O.H. CASAL. 1965. Revisión de las especies del género Euctenodes Waterhouse, 1879 (Diptera, Acalipterae, Streblidae). Notas Biologicas de la Facultad de Ciencias Exactas, Fisicas y Naturales, Zoologia, Corrientes, 5: 3-23.

Gervais, F.L.P. 1844. Atlas de zoologie, ou collection de 100 planches comprenant 257 figures d'animaux nouveaux ou peu connus classés d'après da méthode de M. de Blainville. Avec une explication par M. Paul Gervais. Ouvraze complementaire des dictionnaires et des traités d'Histoire naturelle. Paris, Germer Baillière, 32p.

Graciolli, G. \& A.M. RuI. 2001. Ocorrência de Streblidae (Diptera: Hippoboscoidea) em morcegos (Chiroptera, Phyllostomidae) no nordeste do Rio Grande do Sul, Brasil. Iheringia, Sér. Zool., Porto Alegre, 90: 85-92.

GuÉRIN-MénevilLe, F.E. 1844. Iconographie du règne animal de G. Cuvier... 3. Paris, J.B. Baillière, p. $1-576$

Guerrero, R. 1993. Catalogo de los Streblidae (Diptera: Pupipara) parasitos de murcielagos (Mammalia: Chiroptera) del Nuevo Mundo. I. Clave para los generos y Nycterophilinae. Acta Biol. Venez. 14: 61-75.

. 1994a. Catalogo de los Streblidae (Diptera: Pupipara) parasitos de murcielagos (Mammalia: Chiroptera) del Nuevo Mundo. II. Los grupos: pallidus, caecus, major, uniformis y longipes del genero Trichobius Gervais, 1844. Acta Biol. Venez. 15: 1-18.

1994b. Catalogo de los Streblidae (Diptera: Pupipara) parasitos de murcielagos (Mammalia: Chiroptera) del Nuevo Mundo. IV. Trichobiinae com alas desarrolladas. Bol. Entomol. Venez., n.s., 9: 161-192.

1995a. Catalogo de los Streblidae (Diptera: Pupipara) parasitos de murcielagos (Mammalia: Chiroptera) del Nuevo Mundo. III. Los grupos: dugesii, dunni y phyllostomae del genero Trichobius Gervais, 1844. Acta Biol. Venez. 15: 1-27.

. 1995b. Catalogo de los Streblidae (Diptera: Pupipara) parasitos de murcielagos (Mammalia: Chiroptera) del Nuevo Mundo. V. Trichobiinae con alas reducidas o ausentes y miscelaneos. Bol. Entomol. Venez., n.s., 10: 135-160.

- 1996a. Catalogo de los Streblidae (Diptera: Pupipara) parasitos de murcielagos (Mammalia: Chiroptera) del Nuevo Mundo. VI. Streblinae. Acta Biol. Venez. 16: 1-26.

- 1996b. Streblidae (Diptera: Pupipara) parásitos de los murciélagos de Pakitza, Parque Nacional Manu (Perú), p. 627-641. In: D.E. WILSON \& A. SANDOVAL. MANU: La biodiversidad del sureste del Perú. Washington, D.C., Smithsonian Institution.

1997. Catalogo de los Streblidae (Diptera: Pupipara) parasitos de murcielagos (Mammalia: Chiroptera) del Nuevo Mundo. VII. Lista de especies, hospedadores y paises. Acta Biol. Venez. 17: 9-24.

- 1998a. Notes on Neotropical batflies (Diptera, Streblidae). I. The genus Trichobius, with description of two new species and new subspecies from Venezuela. Acta Parasitologica 43: 86-93.

. 1998b. Notes on Neotropical batflies (Diptera, Streblidae). II. Review of the genus Xenotrichobius. Acta Parasitologica 43: 142-147.

Guerrero, R. \& J.B. Morales-Malacara. 1996. Streblidae (Diptera: Calyptratae) parásitos de 
murciélagos (Mammalia: Chiroptera) cavernícolas del centro y sur de México, con descripción de una especie nueva del género Trichobius. An. Inst. Biol. Univ. Nac. Autón. México, Zool. 67: 357-373.

Guimarães, L.R. 1937. Sobre as especies sul americanas do genero Trichobius (Diptera-Streblidae). Rev. Mus. Paul. 23: 653-666.

. 1941. Notas sobre Streblidae. Pap. Avuls Dep. Zool., São Paulo, 1: 213-222.

1944. Ectoparasitas de aves e mamíferos colecionados em Monte Alegre. Pap. Avuls Dep.

Zool., São Paulo, 2: 15-20.

ICZN (International Commission Of Zoological Nomenclature). 1936. Opinion 128. Nycteribia, 1796, Pupipara and Spinturnix, 1826, Acarine. Smithson. misc. Collns 73: 28-44.

JoBLING, B. 1936. A revision of the subfamilies of the Streblidae, and the genera of the subfamily Streblinae (Diptera, Acalypterea) including a redescription of Metelasmus pseudopterus Coquillet and a description of two new species from Africa. Parasitology 28: 335-380.

. 1938. A revision of the species of the Genus Trichobius (Diptera Acalypterae, Streblidae). Parasitology 30: 358-387.

-1939. On some american genera of the Streblidae and their species, with the description of a new species of Trichobius (Diptera, Acalypterae). Parasitology 31: 486-497.

.1949a. A revision of the species of the genus Aspidoptera Coquillett, with some notes on the larva and puparium of A. clovisi, and a new synonym. Proc. R. Ent. Soc. Lond. (B) 18: 135-144.

- 1949b. Host-parasite relationship between the american Streblidae and the bats, with a new key to the american genera and a record of Streblidae from Trinidad, British West Indies (Diptera). Parasitology 39: 315-329.

-1952. Description of two new species of Ascodipteron from Africa and one species of Nycteribosca from Madagascar (Diptera, Streblidae). Parasitology 42: 126-135.

KesseL, Q.C. 1924. Notes on the Streblinae, a subfamily of the Streblidae (Diptera Pupipara). Parasitology 16: 405-414.

1925. A synopsis of the Streblidae of the world. Jour. N.Y. Ent. Soc. 33: 11-41.

Kolenati, F.A. 1856. Die Parasiten der Chiropteren. Brünn (Rohrer), 51p.

1863. Beiträge zur Kenntnis der Phthirio-Myiarien. Hor. Soc. Ent. Ross. 2: 9-109.

Komeno, C.A. \& A.X. Linitares. 1999. Batflies parasitic on some phyllostomid bats in Southeastern Brazil: Parasitism rates and host-parasite relationships. Mem. Inst. Oswaldo Cruz 94: 151-156.

MAA. T.C. 1965. An interim world list of batflies (Diptera: Nycteribiidae and Streblidae). Jour. Med.

Entomol. 1: 337-386.

Machado-Allison, C.E. 1966. Notas sobre Streblidae (Diptera) de Venezuela I. Las especies del genero Pterellipsis Coquillet. Acta Biol. Venez. 5: 69-79.

MacQuart, M.J. 1852. Sur un nouveau genre de Diptères de la famille des Pupipares, tribu des Phthiromydes, sous le nom de Megistopoda (M. pilatei). Annls Soc. Ent. Fr. 10: 331-333.

Marinkelle, C.J. \& E.S. Grose. 1981. A list of ectoparasites of Colombian bats. Rev. Biol. Trop. 29: $11-20$.

Miranda Ribeiro, A. 1907. Alguns dípteros interessantes. Arch. Mus. Nac., Rio de Janeiro, 14: 231-239.

PERTY, J.A.M. 1833. Delectus animalium articulatorum, quae in itinere per Brasiliam annis MDCCCXVII - MDCCCXX jussu et auspicilis Maximiliani Josephi I. Bavariae regis augustissimi peracto collegerunt Dr. J.B. de Sphix; et Dr. C.F. Ph. de Martius. Fasc. 3. Monachii, F. S. Hübschmann; Lipsiae, Fleischer, p. 125-224.

PESSÒA, S.B. \& A.L. GALVÃo.1936. Novo genero e nova especie de Streblidae (Dipt. Pupipara) parasita do morcego do Brasil. Rev. Ent. 6: 242-248.

PEssôA, S.B. \& L.R. GuimarÃES. 1936. Notas sobre Streblidae (Diptera), com a descripção de um novo genero e duas novas especies. Anais Fac. Med. Univ. São Paulo 12: 255-267.

1940. Nota sobre streblídeos (Diptera) de morcegos de Mato-Grosso, Brasil. Archos Inst. biol., São Paulo, 11: 421-426. 
Reis, N.R.; M.F. MÜeller; E.S. SoARes \& A.L. PERACCHI. 1993. Lista e chaves de quirópteros do Parque Estadual Mata do Godoy e arredores, Londrina, PR. Semina, Ci. Biol. Saúde, Londrina, 14: $120-126$.

Rondani, C. 1878. Muscaria exotica Musei civici Januensis observata et distincta. Fragmentum IV.

Hippoboscita exotica non vel minus cognita. Ann. Mus. Stor. Nat. Gen. 12: 150-169.

Rudow, F. 1871. Einige Pupiparen auf Chiropteren schmarotzend. Ztschr. ges. Naturw. 37: 121-124.

Santos, B.B. DOS 1991. Ocorrência de Streblidae (Diptera) em morcegos no estado do Paraná. Rev.

Setor Ci. Agrárias, Curitiba, 11: 291-292.

SÉGUY, E. 1926. Diptéres exotiques peu connus. Encycl. Entomol. (B) 2 Diptera 3: 192-196.

SPEISER, P. 1900a. Ueber die Strebliden, Fledermausparasiten aus der Gruppe der pupiparen Dipteren.

Arch. Naturg. 66: 31-77.

- 1900b. Ueber die Art der Fortpflanzung bei den Strebliden, nbst synonymischen Bemerkungen. Zool. Anz. 23: 153-154.

TownsEnd, C.H.T. 1891. A remarkable new hippoboscid from Mexico. Ent. News 2: 105-106.

VizotTo, L.D. \& V.A. TADDEI. 1973. Chave para determinação de quirópteros brasileiros. Bol. Ci., São José do Rio Preto, 1: 1-72.

Waterhouse, C.O. 1879. On affinity of the genus Polyctenes Giglioli with description of new species.

Trans. R. ent. Soc. Lond. 1879: 309-312.

WenZEL, R.L. 1970. Family Streblidae. In: N. PAPAVERo (Ed.). A catalogue of the Diptera of the

Americas south of the United States 100. São Paulo, Museu de Zoologia, Univ. São Paulo, 25p. . 1976. The streblid batflies of Venezuela (Diptera: Streblidae). Brigham Young Univ. Sci.

Bull., Biol. Ser., 20: 1-177.

Wenzel, R.L. \& B.V. Peterson. 1987. Streblidae, p. 1293-1301. In: J.F. McAlpine; B.V. Peterson;

G.E. Shewell; H.J. TeSkey; J.R. Vockeroth \& D.M. Wood (Eds). Manual of Neartic Diptera.

Ottawa, Minister of Supply and Services, Vol. 2, Monograph 28, 1332p.

WENZEL, R.L.; V.J. TiPTON \& A. KIEWLICZ. 1966.The streblid batflies of Panama (Diptera: Calyptera:

Streblidae), p. 405-675. In: R.L. WenZEL \& V.J. TIPTON (Eds). Ectoparasites of Panama. Chicago,

Field Mus. Nat. Hist., XII $+861 \mathrm{p}$.

WhitAker JR., J.O. \& R.E. Mumford. 1977. Records of ectoparasites from brazilian manmals. Ent. News 88: 255-258.

WiedeMANN, C.R.W. 1824. Analecta entomologica ex Museo regio Havniensis maxine congesta. Kiliae, Reg. Typogr. Schol., 60p.

ZEvE, V.H. \& D.E. HowELL. 1963. The comparative external morphology of Trichobius corynorhini, T. major, e T. sphaeronotus (Diptera, Streblidae). Part II. The Thorax. Ann. Entomol. Soc. Amer. 56: 2-17.

Recebido em 17.VIII.2000; aceito em 27.VIII.2001. 